\title{
Chapter 5 \\ Ceramic Extrusion Technologies for Fine Grained TRIP Matrix Composite Materials
}

\author{
Christian Weigelt, Marie Oppelt and Christos G. Aneziris
}

\begin{abstract}
Metal-Matrix-Composites (MMCs) based on steel with certain ceramic additions offer a wide range of applications in automotive, construction, and mechanical engineering. These MMCs combine the specific properties of steels such as their room temperature deformation behavior with the advantageous hard but brittle ceramic reinforcements which makes them favorable in crash-absorbing or strengthening components. However, common technologies such as casting or infiltration of ceramic preforms by metal melts suffer from the differences between metal and ceramic material characteristics involved during material processing and from geometrical restrictions. The adaption of the ceramics-derived extrusion technology at ambient temperature on materials established in the powder metallurgy (PM) enables an efficient manufacturing process of advanced fine-grained materials with particularly cellular (lightweight) structures as well as bulk specimens. Using powder raw materials enables a wide range of material combinations between TRIP/TWIP steels and various ceramic components considering the pronounced material characteristics of the composite. Knowing the influence of the raw materials, the processing parameters for shaping and the indispensable thermal processing transforming the formed powders into a solid material is crucial for proper manufacturing of MMCs with tailored characteristics. The joining process for these components extends the applicability of the investigated PM-MMCs.
\end{abstract}

\subsection{Introduction}

Composite materials based on metal and ceramic have been investigated for several years. The principle of combining different materials in order to achieve a new type of material that associates the specific properties of each component, proposes not only improvements of existing products, but also the creation of new materials

C. Weigelt $(\varangle) \cdot$ M. Oppelt · C. G. Aneziris

Institute of Ceramic, Glass and Construction Materials, Technische Universität Bergakademie Freiberg, Agricolastr. 17, 09599 Freiberg, Germany

e-mail: christian.weigelt@ikgb.tu-freiberg.de 
and fields of application. Metal-matrix composites gained in popularity, since they provide a large variety of tailored characteristics, especially due their deformation behavior. Such materials enable various applications in the mobility or engineering sector due to their mechanical properties under static and dynamic loading at ambient temperatures. Further benefits as compared with conventional materials may be achieved by their thermal-, corrosion-, and wear-related properties. MMCs composed of a steel showing a transformation induced plasticity (TRIP) effect offer a matrix material with outstanding ductility, high strength, and reasonably high capacity for absorption of mechanical energy. These properties originate from the strain-induced martensitic phase transformation from austenite to $\alpha^{\prime}$-martensite under mechanical loading. Additionally, the phase transformation can be overlapped by a twinning induced plasticity (TWIP) effect, which further improves the deformability and strain hardening of such steels. The deformation mechanisms are governed by the austenite stability and by the stacking fault energy $\gamma_{\mathrm{SF}}$ (SFE) that depend on the chemical composition of the alloy and on the temperature applied during deformation [1-3]. The material concept covered by the CRC799 is focused on high-alloyed stainless CrMnNi-steels. The SFE determining the dominant deformation mechanism can be estimated by various empirical equations. The presence of austenite and martensite can be predicted from the chemical composition by using the proportions and individual weighting factors for each element of the alloy [4]. The nickel equivalent $\left[\mathrm{Ni}_{\mathrm{eq}},(5.1)\right]$ is calculated from the austenite promoting elements (e.g. $\mathrm{Ni}, \mathrm{C}, \mathrm{Mn}$ ), while the chrome equivalent $\left[\mathrm{Cr}_{\mathrm{eq}},(5.2)\right]$ considers the ferrite stabilizing character of elements such as $\mathrm{Cr}$, $\mathrm{Ti}$, and $\mathrm{Si}$. Apparently, the alloy composition is of great importance for the phase composition and their ability to undergo the desired deformation mechanisms.

$$
\begin{gathered}
\mathrm{Ni}_{\text {eq }}=\mathrm{wt} \% \mathrm{Ni}+30 \times \mathrm{wt} \% \mathrm{C}+18 \times \mathrm{wt} \% \mathrm{~N}+0.5 \times \mathrm{wt} \% \mathrm{Mn} \\
+0.3 \times \mathrm{wt} \% \mathrm{Co}+0.2 \times \mathrm{wt} \% \mathrm{Cu}-0.2 \times \mathrm{wt} \% \mathrm{Al} \\
\mathrm{Cr}_{\mathrm{eq}}=\mathrm{wt} \% \mathrm{Cr}+\mathrm{wt} \% \mathrm{Mo}+4 \times \mathrm{wt} \% \mathrm{Ti}+4 \times \mathrm{wt} \% \mathrm{Al}+1.5 \times \mathrm{wt} \% \mathrm{Si} \\
+0.9 \times \mathrm{wt} \% \mathrm{Nb}+0.5 \times \mathrm{wt} \% \mathrm{~W}+0.9 \times \mathrm{wt} \% \mathrm{Ta}+1.5 \times \mathrm{wt} \% \mathrm{~V}
\end{gathered}
$$

Zirconia $\left(\mathrm{ZrO}_{2}\right)$ ceramics offer enhanced mechanical properties at ambient temperature due to its polymorphism. The polymorphism is associated with the appearance of room temperature stable monoclinic $\left(\mathrm{m}-\mathrm{ZrO}_{2}\right.$, space group $\left.\mathrm{P} 2_{1} / \mathrm{c}\right)$ and high temperature stable tetragonal/cubic $\left(\mathrm{t}-\mathrm{ZrO}_{2}\right.$, space group $\mathrm{P} 4_{2} / \mathrm{nmc}$, and c- $\mathrm{ZrO}_{2}$, space group Fm-3 m, respectively) crystal structures at ambient pressure. The martensitic phase transformation from the tetragonal to the highly distorted monoclinic modification during cooling below $1170^{\circ} \mathrm{C}$ occurs simultaneously with a volume expansion of roughly $3 \%$ and which generates stress in the surrounding material resulting in cracking and failure of pure zirconia components. By the addition of stabilizing agents, such as $\mathrm{MgO}$ (forming magnesia partially stabilized zirconia-Mg-PSZ), the high temperature $\mathrm{ZrO}_{2}$-modifications can be metastably retained at ambient temperature. These polymorphs are capable to undergo a delayed tetragonal to monoclinic phase 
transformation, providing the well-known stress-assisted transformation-toughening mechanism and which results in the specific characteristics of commercial zirconia applications. The distinctive phase transformation triggered by external loading cannot only improve the mechanical properties of ceramics but also reinforce metal-matrix materials.

MMCs based on a TRIP/TWIP steel-matrix with certain ceramic additions have been in focus of several investigations. However, common technologies suffer from the different material characteristics involved during processing. Numerous MMCs have been investigated in the past using a variety of manufacturing processes such as stir casting [5], squeeze casting [6], spray forming [7], infiltration of ceramic preforms $[8,9]$ or powder manufacturing [10-14]. However, these conventional techniques cannot produce cellular structures with a wall thickness on the micron scale, since they are restricted to bulk structures or components. Therefore, powder metallurgy is of great interest in the development of new materials and their processing technologies. The adaption of the ceramics-derived extrusion (also referred to as plastic processing) technology at ambient temperatures on mixtures of steel and ceramic powder raw materials enables an efficient manufacturing of advanced fine-grained materials with particularly cellular (lightweight) structures as well as bulk fabrics. Thus, these materials are applicable in certain applications, such as crash-absorber, engineering or structural components, and damping elements. Figure 5.1 illustrates the latitude of the plastic enabling honeycomb structures with various cell geometries and cell densities (indicated as channels per square inch-cpsi) at cell widths of $250-450 \mu \mathrm{m}$ and relative densities of $0.3-0.4$.

The extrusion process is widely known in the production of ceramic materials covering, among others: tiles, rods, and thermocouple protection tubes. This process was initially applied to natural plastic raw materials (clay) and later adapted to non-plastic raw materials. In the latter case, solid powders are transferred into a room-temperature plastic paste by admixing organic additives and solvents (usually

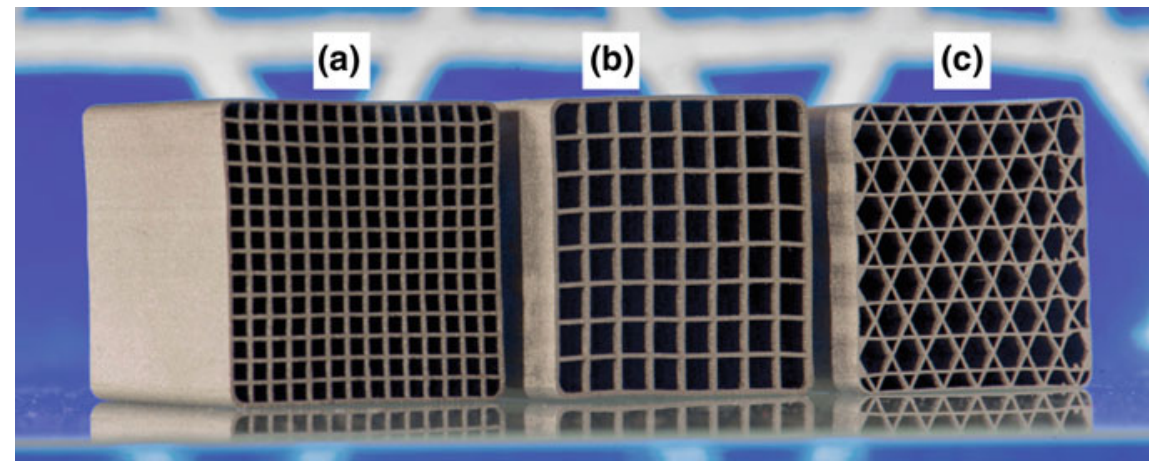

Fig. 5.1 Variants of cellular structures manufactured with the ceramics-derived extrusion process at room temperature: honeycombs with $196 \mathrm{cpsi}(\mathbf{a}), 64 \mathrm{cpsi}$ (b) and with the $172 \mathrm{cpsi}$ Kagome lattice structure (c), all variants with outer dimension $25 \times 25 \mathrm{~mm}^{2}$ 
water). Then, the paste can be easily shaped by forcing it through a rigid die with the geometry of the component to be produced. The thermal treatment comprising drying, removal of organic additives (debinding) at moderate temperatures and the sintering transfers the materials into their final state (see Fig. 5.2). Previous investigations on alumina [15] materials successfully demonstrated the efficient processing of honeycomb structures, and therefore, the processing has been selected as the most suitable method for forming metal-ceramic composite structures in the frame of the present study. Beyond, the ceramics-derived processing involves the cost- and material-efficient near-net shaping at ambient temperatures and the processing of any steel/ceramic ratio. However, the pressureless sintering implies higher remaining porosities and pronounced interactions between the metal and ceramic components as compared to MMCs prepared by pressure-assisted consolidation methods such as hot-pressing (HP) [11] or spark plasma sintering (SPS) [10].

Composite materials based on austenitic stainless steel with particulate reinforcement prepared via cold extrusion are in focus of the present work. The correlation of the initial materials, the processing and the resulting properties of the materials are presented. A very important part of this work deals with chemical and microstructural interactions between the components steel and the reinforcing ceramic particles during sintering. Hereto, no studies on magnesia partially stabilized zirconia in conjunction with high manganese steels have been reported.

The addition of ceramic particles to a ductile matrix increases the strength, but lowers the material's deformability by inducing typical damage events like debonding, particle fracture or crack coalescence even at moderate fractions of ceramic particles. Thus, improving the interface bonding between the metal matrix and the zirconia particles is of major importance. Wittig et al. [8] reported the pressureless infiltration of zirconia preforms with a CastX38CrMoV5-1 (AISI H11) steel by adding $20 \mathrm{wt} \%$ elemental titanium. Previous investigations revealed similar results with alumina preforms [16]. The high diffusibility of $\mathrm{Ti}$, the formation of $\mathrm{TiO}_{x}$ interlayers, and the improved wetting behavior promote sufficient infiltration and the formation of reliable interface boundaries. Titanium is also used as an active component in the brazing of zirconia/zirconia or zirconia/alloy joints [17, 18]. Beyond

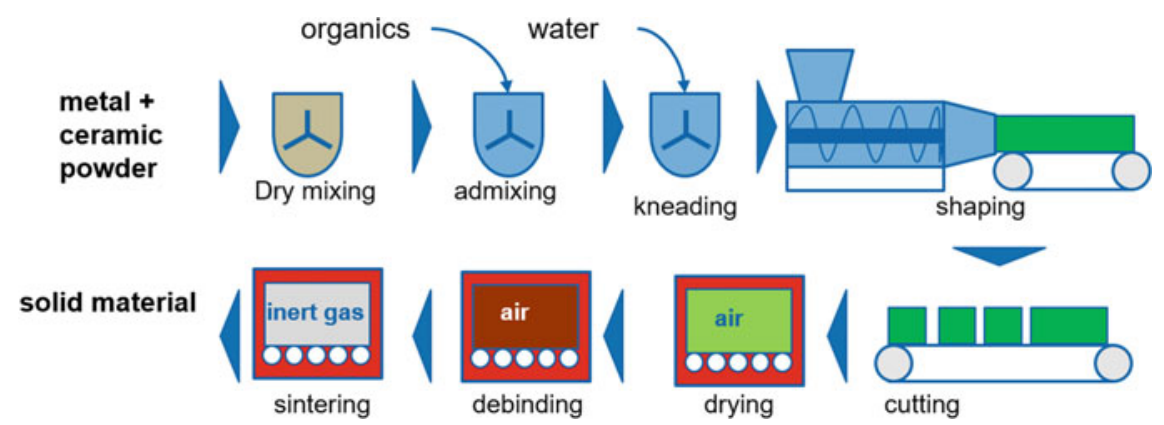

Fig. 5.2 Scheme of the plastic processing route 
this, titanium is known for its partial stabilization efficiency in zirconia ceramics by sintering in inert gas atmosphere [19, 20]. Variants of steel and magnesia partially stabilized zirconia were admixed with minor fractions of titanium in order to improve the interface formation during sintering in the frame of this work. The influence of the active interface agent on the mechanical properties has been tested by quasistatic compression tests. The microstructure and the phase compositions were investigated in order to correlate the mechanical response with the desired phase transformations of TRIP steel and zirconia.

Nevertheless the aspiration of improving the mechanical behavior, especially the increase of the specific energy absorption (SEA) capacity, leads to intensive investigations of the raw materials, the selection of materials, the adaption of process parameters and finally to the knowledge of the processing-characteristic-knowledge of a branch of composite materials. Not only the well-known zirconia reinforcing particles but also the introduction of alternative ceramics led to significant improvements of the material properties. In general, the steel/zirconia interface shows destabilization due to the diffusion of $\mathrm{Mg}$ out of the particles and the formation of precipitations at the metal/ceramic interface as a result of indispensable thermal treatment at temperatures inappropriate for zirconia sintering. These $\mathrm{ZrO}_{2}$ particles with high amounts of non-transformable monoclinic zirconia are loosely embedded in the metal matrix. Thus, the ability of the reinforcing phase transformation is restricted to the low remaining amount of tetragonal/cubic zirconia. The alloying elements of TRIP/TWIP steels are also prone to diffusional interchange which boosts the interface formation but also the shift of the steel composition. But the interfacial reactions can also improve the material characteristics when exploiting alternative reinforcing ceramics. By replacing zirconia with aluminium titanate $\left(\mathrm{Al}_{2} \mathrm{TiO}_{5}\right)$ a new family of MMCs with advanced mechanical properties under compressive and under tensile deformation is generated.

Furthermore an important issue in this work was the joining of MMCs using a ceramic-derived technology. Bulk specimens from the pure CrMnNi steel, and MMC variants reinforced with 5 or $10 \mathrm{vol} \%$ magnesia partially stabilized zirconia were used as joint partners. The samples were prepared via the ceramics-derived extrusion technology and different material combinations were joined in their dry green state using an aqueous paste to form the bonding. The mechanical testing comprised quasistatic tensile deformation tests of the base materials and of the sinter-joint variants at room temperature. The microstructural analyses revealed considerable differences between the ceramic joining process and the conventional welding of steel materials which is beneficial in future practical applications [21, 22]. 


\subsection{Experimental Details}

\subsubsection{Plastic Processing of Steel/Zirconia Composite Materials}

Numerous experiments have been performed in order to evaluate proper material compositions, processing parameter and thermal treatment conditions. The initial plastic pastes based on the extrusion of alumina honeycombs [15] as listed in Table 5.1 are prepared with a standardized grade steel powder of type AISI 304 (German grade 1.4301) [23-25]. Various powder types were used in the frame of the present study due to the intense research on the alloying concept and the related mechanical characteristics (cf. Table 5.1). The steel variants and their chemical compositions are summarized in Table 5.2. All steel powder variants (TLS, Germany) were manufactured via the gas atomization process which resulted in the formation of mainly spherical shape particles with some satellite particles and a few imperfections (see exemplary Fig. 5.3). Three variants of magnesia partially stabilized zirconia were used in the frame of the present study. Their compositions are given in Table 5.3.

Table 5.1 Composition of the initial mixtures, in wt $\%$ [23]

\begin{tabular}{l|l|l|l|l|l}
\hline \multirow{2}{*}{ Material } & \multicolumn{4}{|l|}{ Raw materials } & \multicolumn{2}{l}{ Recipes } & \multicolumn{2}{l}{} \\
\cline { 2 - 6 } & Type & Supplier & $0 \mathrm{Z}$ & $5 \mathrm{Z}$ & $10 \mathrm{Z}$ \\
\hline Austenitic steel & $\begin{array}{l}\text { AISI } 304 \\
d_{50}=45 \mu \mathrm{m}\end{array}$ & TLS, Germany & 95.50 & 91.84 & 88.17 \\
\hline $\begin{array}{l}\mathrm{ZrO}_{2} \text { with 3.5 wt\% } \\
\mathrm{MgO}\end{array}$ & $\begin{array}{l}\text { PMG3.5 } \\
d_{50}=2 \mu \mathrm{m}\end{array}$ & Unitech, UK & - & 3.66 & 7.32 \\
\hline Plasticizer flour & HW FGB & $\begin{array}{l}\text { Kampffmeyer, } \\
\text { Germany }\end{array}$ & 2.60 & 2.60 & 2.58 \\
\hline Tenside & Denk mit & Henkel, Germany & 0.40 & 0.40 & 0.43 \\
\hline Dispersant & Castament FS 60 & Degussa, Germany & 0.15 & 0.15 & 0.15 \\
\hline $\begin{array}{l}\text { Plasticizer methyl } \\
\text { cellulose }\end{array}$ & HPMC 874 & Aqualon, Germany & 1.35 & 1.35 & 1.35 \\
\hline Water & Deionized & - & 4.5 & 4.8 & 5.0 \\
\hline
\end{tabular}

Table 5.2 Chemical composition of steel powder variants, in wt $\%$

\begin{tabular}{l|l|l|l|l|l|l}
\hline Type & Fe + Others & $\mathrm{Cr}$ & $\mathrm{Mn}$ & $\mathrm{Ni}$ & $\mathrm{C}$ & $\mathrm{Si}$ \\
\hline PMX2CrMnNi18-1-8A & Bal. & 18.1 & 1.4 & 8.3 & 0.02 & 0.4 \\
\hline PMX2CrMnNi18-1-8B & Bal. & 18.3 & 1.4 & 8.1 & 0.02 & 0.3 \\
\hline PMX1CrMnNi18-1-9 & Bal. & 18.4 & 1.1 & 9.3 & 0.01 & 0.7 \\
\hline PMX5CrMnNi18-1-8 & Bal. & 17.5 & 1.3 & 8.4 & 0.05 & 0.4 \\
\hline PMX5CrMnNi17-7-3 & Bal. & 16.7 & 7.1 & 3.4 & 0.05 & 0.9 \\
\hline
\end{tabular}



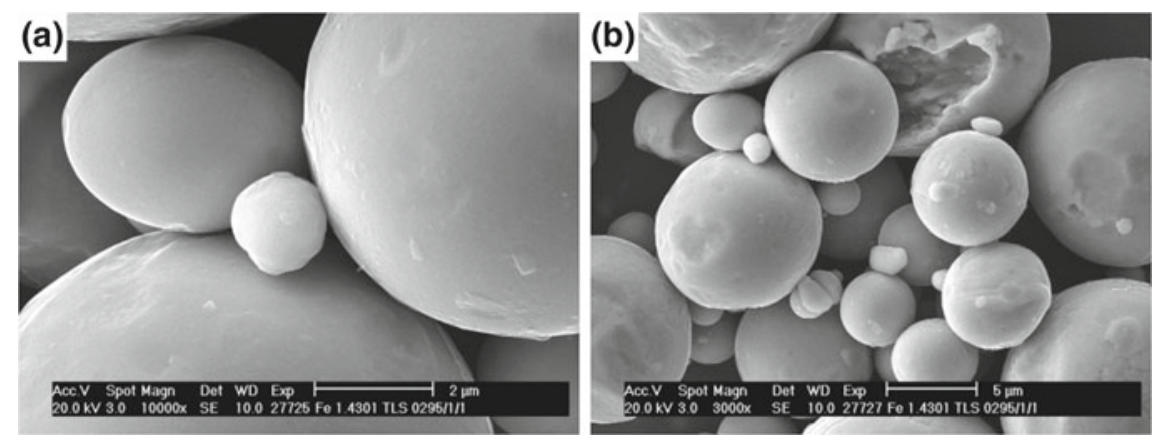

Fig. 5.3 SEM image of the as-delivered spherical steel powder at different magnification (PMX2CrMnNi18-1-8B)

Table 5.3 Composition of the zirconia powder variants, in wt $\%$

\begin{tabular}{l|l|l|l|l|l|l|l}
\hline Type & Supplier & $\mathrm{ZrO}_{2}+$ Others & $\mathrm{MgO}$ & $\mathrm{SiO}_{2}$ & $\mathrm{Al}_{2} \mathrm{O}_{3}$ & $\mathrm{TiO}_{2}$ & $\mathrm{HfO}_{2}$ \\
\hline PSZ1 & Unitech, UK & Bal. & 3.4 & n.m. & 0.7 & 0.2 & 0.8 \\
\hline PSZ2 & Saint-Gobain, USA & Bal. & 2.8 & 0.4 & 0.4 & 0.1 & 1.7 \\
\hline PSZ3 & Saint-Gobain, USA & Bal. & 3.4 & 2.4 & 0.6 & 0.1 & 1.7 \\
\hline
\end{tabular}

Recipe $0 \mathrm{Z}$ consists of $100 \mathrm{vol} \%$ TRIP steel and recipes $5 \mathrm{Z}$ and $10 \mathrm{Z}$ are based on 95 or $90 \mathrm{vol} \%$ TRIP steel with 5 or $10 \mathrm{vol} \%$ zirconia, respectively. In a further step, the plasticizers and water have been added to the batch during mixing. Because of a piston extruder (ECT, Germany), honeycombs $25.5 \mathrm{~mm} \times 25.5 \mathrm{~mm}$ with 164 channels ( $200 \mathrm{cpsi}$ ) and a wall thickness of $250 \mu \mathrm{m}$ have been extruded. The applied pressure was between 10 and $11 \mathrm{MPa}$. After extrusion, cube-shaped samples $(25.5 \mathrm{~mm} \times 25.5 \mathrm{~mm} \times 25.5 \mathrm{~mm})$ have been cut before stepwise water-removal in an air-circulated dryer. After drying, the debinding process has been carried out at $350{ }^{\circ} \mathrm{C}$ for $90 \mathrm{~min}$ in air in the same aggregate. The binder-free samples have been placed in an alumina crucible and protected against $\mathrm{O}_{2}$ contamination by a Ti casketing. The samples have then been sintered at $1350{ }^{\circ} \mathrm{C}$ for $2 \mathrm{~h}$ in an electrical furnace with high purity flushing Argon atmosphere.

Microstructure characterization was performed using scanning electron microscopy (SEM), energy dispersive X-ray analysis (EDS) and electron backscatter diffraction (EBSD). In addition, phase labeling was performed on sintered surfaces by $\mathrm{X}$-ray diffraction (XRD) with $\mathrm{Cu}-\mathrm{K} \alpha$ radiation. The relative phase content of zirconia was determined by the method described by Evans et al. [26]. The open porosity, the average pore radius and the pore size distribution of the sintered samples were measured by mercury porosimetry. The macroscopic structure of the honeycomb samples after deformation was examined by optical microscopy of metallographic sections. The mechanical in-plane testing of the sintered specimens was carried out under compressive loading in a $500 \mathrm{kN}$ servohydraulic universal testing machine type MTS 880 with a displacement rate of $0.016 \mathrm{~mm} / \mathrm{s}$ at ambient temperature. 
Table 5.4 Composition of mixtures for Ti-activated interface formation, in vol\% [27]

\begin{tabular}{l|c|l|l|l|l}
\hline Recipe & $0 Z$ & $10 Z$ & $10 Z-1 T$ & $10 Z-2 T$ & $10 Z-3 T$ \\
\hline Stainless steel & 100 & 90 & 89 & 88 & 87 \\
\hline Zirconia & 0 & 10 & 10 & 10 & 10 \\
\hline Titanium & 0 & 0 & 1 & 2 & 3 \\
\hline
\end{tabular}

A gas-atomized high-purity $>99.7 \%$ Titanium powder (TLS, Germany) with a mean diameter of $13 \mu \mathrm{m}$ and a spherical particle shape was used in some tests as interface activation agent. The basic composition for MMC production was a mixture of $90 \mathrm{vol} \%$ steel (PMX5CrMnNi18-1-8) and 10 vol\% zirconia (see Table 5.4). In MMC compositions with minor titanium fractions $(1,2$, or $3 \mathrm{vol} \%)$ of the matrix material were replaced by Ti powder. Additionally, the pure steel specimens provide a reference material without any additions. Taking the interest of interface reactions and the mechanical properties into consideration, a bulk sample geometry was used, but prepared from a modified processing route.

\subsubsection{Composite Variants with Additions of Zirconia and/or Aluminium Titanate}

Further work was conducted on the development of alternative reinforcing mechanisms since the zirconia particles are prone to undergo the tetragonal to monoclinic phase transformation during thermal processing of the composite materials. Alumina and yttria are well established as reinforcing additions for steel-matrix composites $[28,29]$. However, the alumina particles show no phase transformation and insignificantly interface formation. A new approach is the introduction of aluminium titanate as a reinforcing material which is a promising refractory material due to its excellent thermal properties but not prestigious for its mechanical properties.

Bulk specimens were prepared by the well-established ceramic-extrusion technology with an austenitic stainless steel of type PMX5CrMnNi17-7-3 (see Table 5.2) with a median diameter of $18.1 \mu \mathrm{m}$. The reference materials with the standard zirconia reinforcing powder were prepared from the commercially available Mg-PSZ of type PSZ2 (cf. Table 5.3). Aluminium titanate was synthesized from a stoichiometric mixture of high-purity 99.8 wt\% alumina Martoxid MR70 (Martinswerk, Germany) and $98 \mathrm{wt} \%$ titania Hombikat N100 (Sachtleben, Germany) since proper batches are not commercially available. The addition of $6 \mathrm{~mol} \%$ of a of high-purity grade $(98 \%)$ $\mathrm{MgO}$ powder (neoLab, Germany) improved the thermal stability and protected the aluminium titanate from decomposition on cooling after reactive sintering. The mixture was pre-fired at $1400{ }^{\circ} \mathrm{C}$ in an oxidizing atmosphere in order to ensure high $\mathrm{Al}_{2} \mathrm{TiO}_{5}$ formation, and crushed after cooling to obtain powder fineness similar with the zirconia powder. The $\mathrm{Al}_{2} \mathrm{TiO}_{5}$ mean particle diameter was $4.2 \mu \mathrm{m}$ and consisted of $95 \%$ aluminium titanate with minor residues of unreacted alumina and titania 
Table 5.5 Composition of mixtures, in vol\%

\begin{tabular}{l|c|c|l|l|l|l|l}
\hline Recipe & $0 \mathrm{Z}$ & $5 \mathrm{Z}$ & $10 \mathrm{Z}$ & $5 \mathrm{AT}$ & $10 \mathrm{AT}$ & $2.5 \mathrm{ZAT}$ & 5ZAT \\
\hline Steel & 100 & 95 & 90 & 95 & 90 & 95 & 90 \\
\hline Zirconia & 0 & 5 & 10 & 0 & 0 & 2.5 & 5 \\
\hline Tialite & 0 & 0 & 0 & 5 & 10 & 2.5 & 5 \\
\hline
\end{tabular}

according to X-ray analysis. The basic composition $0 \mathrm{Z}$ refers to the pure steel material without any ceramic additions. The composite variants were prepared with solely zirconia $(\mathrm{Z})$ or aluminium titanate (AT) or with balanced fractions of both (ZAT) at a total fraction of 5 or 10 vol\% (see Table 5.5).

The plastic processing was similar to previous materials with certain modifications of the binder system and the water fraction necessary for shaping. The specimens were heated up to $450{ }^{\circ} \mathrm{C}$ in an oxidizing atmosphere, applying a heating gradient of $1 \mathrm{~K} / \mathrm{min}$ and a dwell time of $30 \mathrm{~min}$ at maximum temperature to eliminate organics from the extrusion process. After cooling to room temperature (at a rate of $1 \mathrm{~K} / \mathrm{min}$ ), the specimens were reloaded into a second furnace with a graphite lining and graphite heating elements (Xerion, Germany). The sintering step was conducted in a flushing argon atmosphere using a heating rate of $5 \mathrm{~K} / \mathrm{min}$ and a maximum temperature of $1350{ }^{\circ} \mathrm{C}$ and a dwell time of $2 \mathrm{~h}$ at the maximum temperature before cooling with a maximum cooling gradient of $5 \mathrm{~K} / \mathrm{min}$.

The fired specimens were processed to a cylindrical geometry $(6 \mathrm{~mm}$ in diameter and height) for compressive loading tests, as well as to round tensile specimens with a gauge diameter of $5 \mathrm{~mm}$ and a gauge length of $30 \mathrm{~mm}$ according to DIN EN ISO 6892-1 for tensile loading tests. The tensile test series were performed with a $100 \mathrm{kN}$ universal testing machine of type Zwick 1476. Compression tests utilised a $200 \mathrm{kN}$ servo-hydraulic testing machine of type MTS 810. All tests were carried out at a quasistatic nominal strain rate of $0.001 \mathrm{~s}^{-1}$ at room temperature.

\subsubsection{Innovative Joining of Powder Metallurgically Processed TRIP/TWIP Steel Materials}

The manufacturing of a composite structure by extrusion is limited to a uniform cross section throughout its entire length, which limits later use. Thus, the availability of a reliable (mechanical) joining technique is a major task in the development of MMCs for commercial applications. Fundamental research was performed on the adaption of a ceramics-derived joining process by adding a slurry on the joining partners at room temperature with the subsequent thermal processing.

Pure steel specimens, the composite variants, and the joining paste were composed of the steel powder batch PMX5CrMnNi17-7-3 (see Table 5.2). The ceramic component was the commercially available magnesia partially stabilized zirconia of type PSZ2 (cf. Table 5.3) [22, 30]. The basic composition (0Z) corresponds to $100 \%$ 
steel without any ceramic additions. Composite mixtures were prepared with fractions of $5 \mathrm{vol} \%$ (5Z) or $10 \mathrm{vol} \%$ (10Z) zirconia in their total solids composition. The powders were mixed for $90 \mathrm{~min}$ in their dry state before adding the organic binder system and water. Rods of $11 \mathrm{~mm}$ in diameter were extruded using a single-screw extruder of type LK III 2A (Linden, Germany) at ambient temperature. The water was removed stepwise in an air circulated dryer applying a maximum temperature of $110{ }^{\circ} \mathrm{C}$. Dried samples of each composition were cut to a length of $50 \mathrm{~mm}$ and the surfaces to be joined were then polished with a rotary grinding machine to obtain a smooth surface.

The aqueous joining paste was prepared from pure metal powder and water with a ratio of $9: 1$ by weight. In addition, an organic binder system composed of $1.0 \mathrm{wt} \%$ KM2000 (Zschimmer \& Schwarz, Germany), 0.6 wt\% KM1001 (Zschimmer \& Schwarz, Germany) and 2 wt\% Optapix G1457 (Zschimmer \& Schwarz, Germany) was necessary in order to ensure a sticky paste with well dispersed steel particles.

The joining paste was brushed on the polished end faces of the partners to be joined immediately before these specimens were manually assembled which led to some leaking of the paste and, thus, complete filling of the gap between both parts. The joined specimens were placed on the firing auxiliaries and handled without any rigid clamping during further processing. Then the samples were again dried stepwise in an air circulated dryer starting at $40{ }^{\circ} \mathrm{C}$ and increasing to a maximum temperature of $110^{\circ} \mathrm{C}$. Debinding and sintering was performed as shown before. The fired specimens were machined to round tensile loading test geometry with a gauge diameter of $4 \mathrm{~mm}$ and a gauge length of $25 \mathrm{~mm}$ according to DIN EN ISO 6892-1. The test series with 5-9 samples of each variant were performed at room temperature with a $50 \mathrm{kN}$ universal tensile testing machine of type Tiratest 2850 (Germany) at a quasistatic nominal strain rate of $0.001 \mathrm{~s}^{-1}$. Microstructural characterization was conducted using light optical microscopy and scanning electron microscopy (SEM, Philips XL30). Energy dispersive X-ray analysis (EDS, EDAX Inc., USA) complemented the microstructural study.

Hardness profiles were recorded using a LECO M400 micro hardness tester. Measurement of the profiles was carried out after Vickers procedure with HV0.3 $(2.94 \mathrm{~N}, 10 \mathrm{~s}$ load duration) in a triple row with a total length of $6 \mathrm{~mm}$ and $100 \mu \mathrm{m}$ increment. Furthermore, macro hardness was likewise measured on a conventional hardness testing device after Vickers with HV10 (98.04 N, $10 \mathrm{~s}$ load duration).

\subsection{Results and Discussion}

\subsubsection{Characteristics of Materials Prepared via Plastic Processing}

The many opportunities of geometries processed via the ceramics-derived extrusion technology are illustrated in Fig. 5.4. Lightweight honeycomb structures as well as 


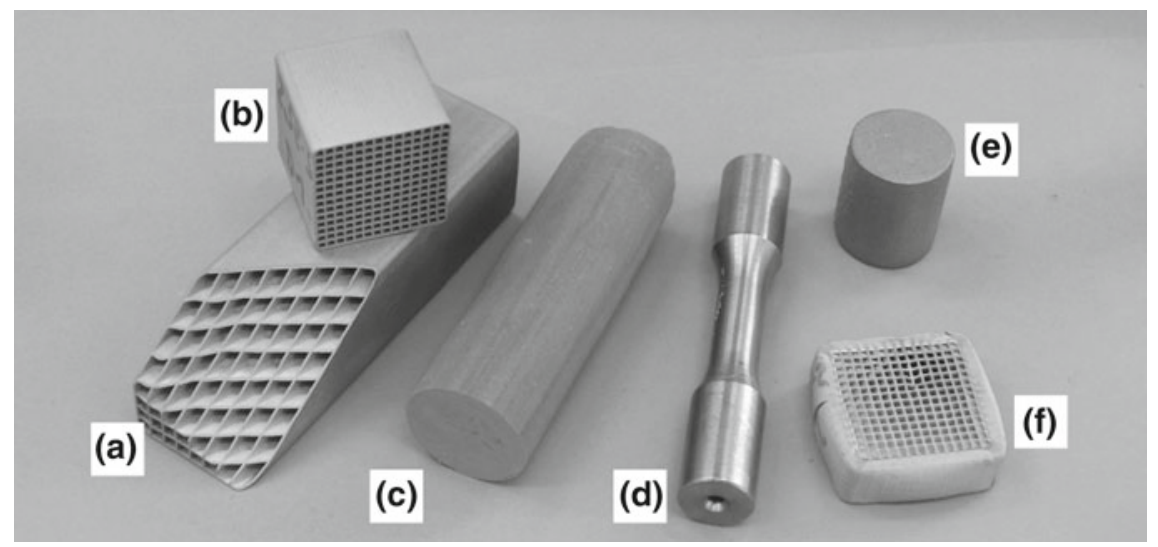

Fig. 5.4 Variations of sample geometries produced by the powder metallurgical route via extrusion: honeycomb structures with $64 \mathrm{cpsi}$ (a) and $200 \mathrm{cpsi}$ (b), green body rod (c) for fatigue specimens (d) and compressive test (e), $200 \mathrm{cpsi}$ honeycomb at 50\% compressive strain (f) [24]
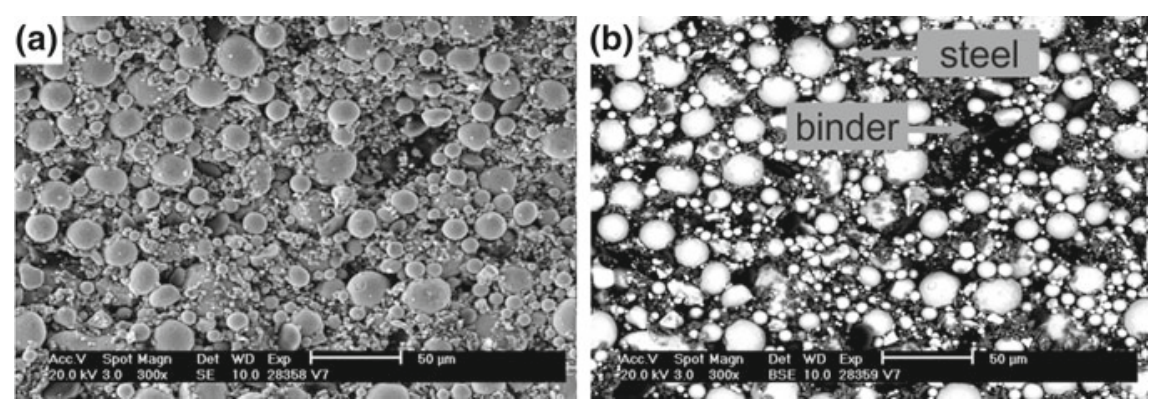

Fig. 5.5 SEM-image of a honeycomb structure (exemplary material variant without any ceramic additions) after drying with steel particles (bright) and polymer binder (dark) in secondary electron mode (a) and backscatter electron mode (b) [24]

bulk specimens can be processed with almost similar plastics pastes enabling a large variety of sample geometries. Thus, the mechanical testing, e.g. under compressive or under tensile loading tests, fatigue tests and ductility tests can be performed with respect to mutual applications.

Figure 5.5 illustrates the microstructure of the $100 \%$ steel sample without any ceramic additions after the extrusion process and their dry state. The spherical steel particles are surrounded uniformly by the organic additives. A certain porosity is derived from the particle size distribution of the metal powder and the removed water portion necessary for sound extrusion. The microstructure undergoes fundamental changes during thermal processing. The organic components, as being removed during debindering, cause not only porosity but also impurities (ash) and carbon residue from inappropriate settings. The pressureless sintering at temperatures slightly below the melting temperature of the metal initiates the final consolidation. 
The carbon content is crucial for the mechanical characteristics of TRIP/TWIP steel-matrix materials since carbon crucially affects the deformation mechanism of the steel matrix. Furthermore, the presence of enhanced carbon fractions promotes the formation of carbides during sintering which are likely to decrease the strength and ductility of the material. Thus, the complete removal of the organic processing aids during thermal treatment is essential for the mechanical properties of powder metallurgically processed materials. The carbon fraction decreases by increasing the maximum temperature during debindering. However, the thermal binder removal at higher temperatures is limited due to the oxidation of the steel particles. These oxides are thermodynamically stable during sintering causing undesired inclusions even in the material without any further addition of ceramic particles. The binder removal for honeycomb structures is possible with heating rates up to $2 \mathrm{~K} / \mathrm{min}$. Faster heating results in cracks and incomplete binder removal in the center of test specimens. Figure 5.6 presents the microstructure of a typical sample fracture surface of the composite variant $5 \mathrm{Z}$ after sintering at $1350^{\circ} \mathrm{C}$. Here, a continuous steel matrix with well dispersed zirconia particles can be seen. The fine grained ceramic particles usually appear as agglomerates in the interstices of the coarser grained metal. According to EDS-analysis three different regions can be identified. First, the composition of the steel matrix which largely correlates with the chemical composition of the asdelivered material, and second, the ceramic regions with dominating zirconia content can be observed. Further on, particles that were not present in the starting materials and that were most likely formed during sintering are randomly spread throughout the whole material. They are characteristically composed of varying compositions of chromium, manganese, magnesium, aluminium and silicon and they are detectable among all materials processed via the plastic processing. They are particularly not exclusively present in the composite variants but also in pure steel samples.

Another aspect of the pressureless sintering is the thermally induced tetragonal to monoclinic phase transformation of the zirconia particles. Figure 5.7 presents the EBSD-phase analysis of zirconia agglomerates (dispersed in PMX1CrMnNi18-1-9) in the material variant $5 \mathrm{Z}$ after sintering, and after $20 \%$ compressive deformation [3].
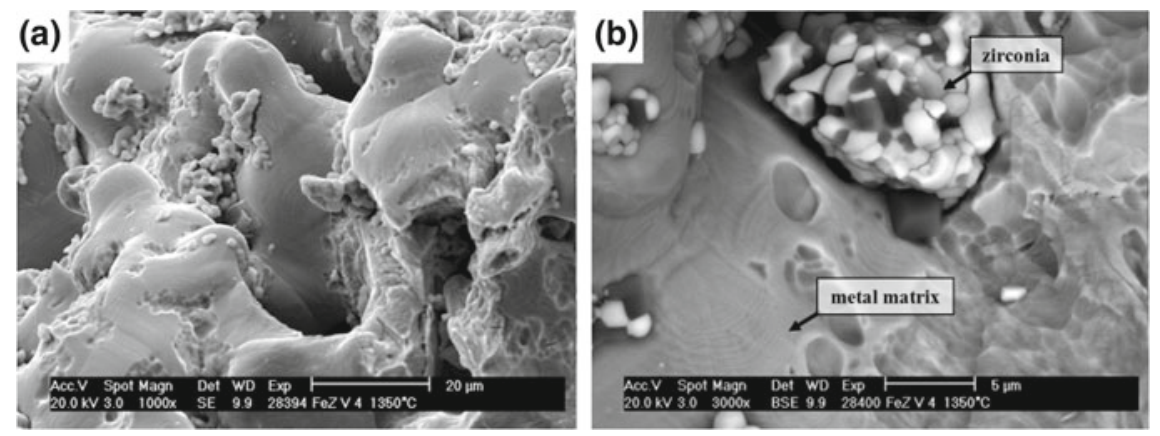

Fig. 5.6 SEM image of a typical fracture surface region of the composite material $5 \mathrm{Z}$ in the as-fired state at different magnifications [3] 

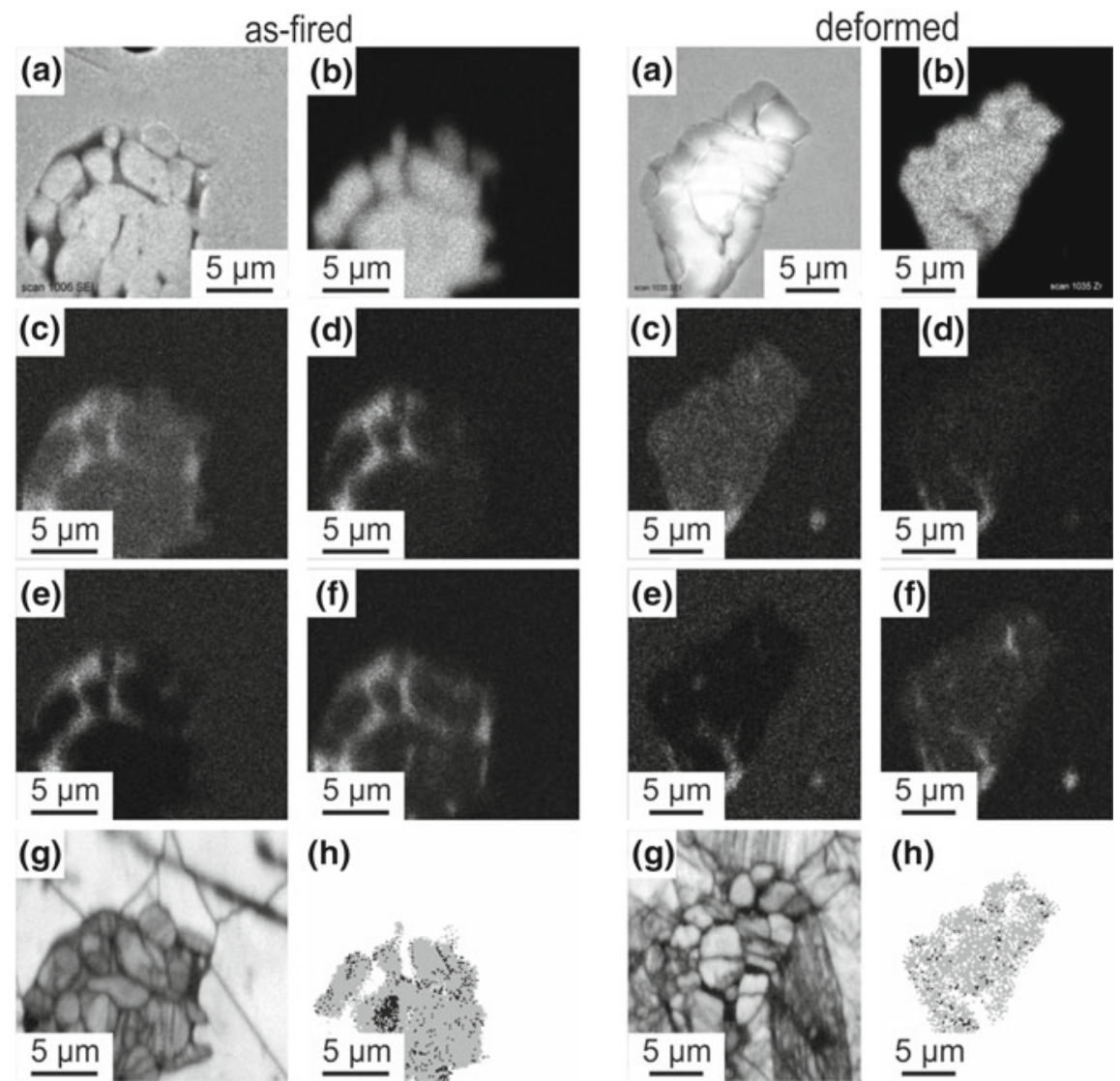

(h)

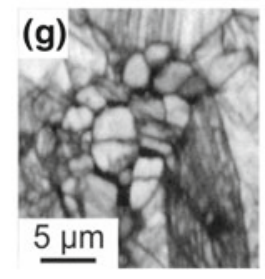

(h)
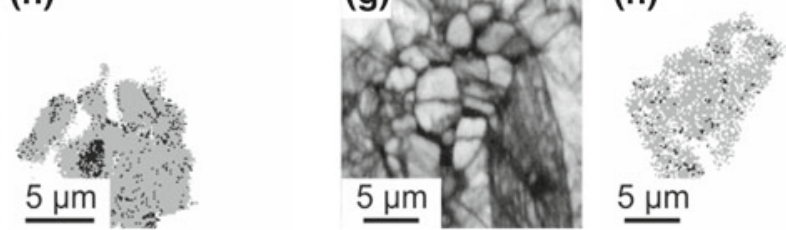

Fig. 5.7 Cross-section of zirconia agglomerates in the as sintered state A) and after 20\% compressive strain B) with the composition 5Z: a SEI, b EDS Zr map, c EDS O map, d EDS Mg map, e EDS Mn map, f EDS Si map, $\mathbf{g}$ EBSD quality map, h EBSD phase map showing t/c-ZrO $\mathrm{Z}_{2}$ (black), and $\mathrm{m}-\mathrm{ZrO}_{2}$ (gray) [3]

Both spots show zirconia agglomerates embedded in the steel matrix. The EDS maps clarify the edge between metal and ceramic phase enabling separated phase analysis. The EBSD image quality for zirconia particles is lower in comparison to steel in case of the as-fired specimen. After plastic deformation, both components appear with nearly the same validity due to distorting the crystal lattices during deformation. The dominating amount of non-metastable monoclinic phase after sintering is obvious. Nevertheless, the $\mathrm{m}-\mathrm{ZrO}_{2}$ quantity is increased after compressive deformation.

The interactions between the steel matrix and the zirconia particles were investigated in detail from model mixtures of the zirconia variants PSZ2 and PSZ3 with solely additions of the main alloying elements ( $\mathrm{Cr}, \mathrm{Ni}, \mathrm{Mn}$ and $\mathrm{Fe})$ [21]. The addition of $\mathrm{Cr}$ leads to several chemical reactions associated with a change of phase composition in zirconia matrix. Up to $18 \%$ of the steel mass are delivered as chromium, which 

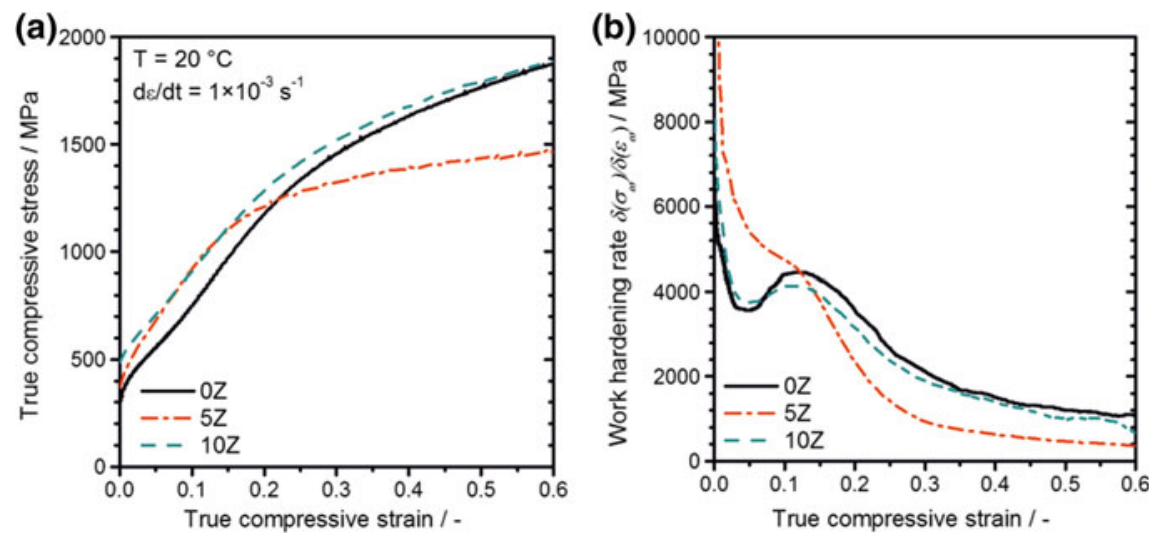

Fig. 5.8 Mechanical behavior of the compressed specimens indicating the reinforcing effect of Mg-PSZ on the compressive yield strength and on the work hardening: a flow stress curves, $\mathbf{b}$ work hardening rates [31]

reflects the importance of PSZ-Cr interactions in the present composite materials. Sintering magnesia partially stabilized zirconia at $1300-1400{ }^{\circ} \mathrm{C}$ causes pronounced changes in the phase composition with a minor fraction of tetragonal and/or cubic $\mathrm{ZrO}_{2}$ after firing. Additions of $\mathrm{Mn}$ and $\mathrm{Fe}$ already start reacting with zirconia matrix when sintering at $1300^{\circ} \mathrm{C}$ leading to either destabilization (Fe) or stabilization (Mn). Further heating to $1400{ }^{\circ} \mathrm{C}$ indicates the reaction of chromium with stabilizer magnesia to form magnesia chromite. Variations of the dwell time at maximum temperature have negligible effects on $\mathrm{ZrO}_{2}$ phase composition. In contrast $\mathrm{Ni}$ has no significant influence on the sintering progress and phase composition of the fired zirconia.

Figure 5.8 depicts the stress-strain behavior of the materials under quasistatic compressive deformation. The composite materials showed higher stresses over a wide range of strain than the unreinforced material $0 \mathrm{Z}$. The yield strength at $0.2 \%$ plastic compressive strain was $\approx 70 \mathrm{MPa}$ higher for both MMC variants as compared with the pure steel specimens. The composites $10 \mathrm{Z}$ revealed a pronounced strengthening effect under quasistatic compressive loading up to a deformation degree of approximately $45 \%$. In contrast, the strengthening effect of material $5 \mathrm{Z}$ was exhausted when exceeding $18 \%$ compressive strain. Comparing these results with values from SPS material prepared from similar materials indicates the dominating effect of the consolidation process [28]. The lower strengthening effect of the present specimens is due to higher porosity in the matrices, the larger austenite grain size, and the distinctive reactions at the steel/zirconia interfaces. Because of damage initiation and propagation, the compression stress of composite materials dropped below the values measured for the pure steel specimen at higher strain levels. The characteristics of the matrix material mainly controlled the stress-strain level and the deformation behavior of all specimens tested. The matrix strain hardening was driven by the dislocation movement, by the accumulation of dislocations and by the strain-induced $\alpha^{\prime}$-martensite formation (TRIP effect) [28]. The work hardening rates, as shown in 
Fig. 5.8, illustrate the strengthening effect of the ceramic particles in a certain range of strain followed by a decreasing work hardening rate at further deformation [31].

A similar material behavior was observed under quasistatic tensile loading (see Fig. 5.9). As expected, the pure steel specimens exhibited the highest tensile strength and fracture strain among all materials tested. The composite materials suffer from poor interfacial connections between the metal matrix and zirconia reinforcing particles. Therefore, the presence of ceramic dispersed within the ductile steel matrix lowers the material's deformability, inducing typical damage events like debonding, particle fracture or crack coalescence, which initiates MMC's failure at lower strain $[10,32,33]$. This effect is more pronounced under tension than under compression. The influence of the ceramic fractions on the MMCs' tensile yield strengths is negligibly small. Nevertheless, the composite variant $5 Z$ shows a higher stress level than the pure steel at the expense of their ductility. As similar to compressive deformation the material $5 \mathrm{Z}$ fails at lower strain than specimens with 10 vol\% zirconia which is most likely caused by larger pores and voids in the matrix material. The in situ tests revealed the kinetics of strain-induced $\alpha^{\prime}$-martensite during deformation. The $0 \mathrm{Z}$ specimens exhibited the highest overall percentage of strain-induced $\alpha^{\prime}$-martensite. The lower formation of strain-induced $\alpha^{\prime}$-martensite in the composite variants was in accordance with the less pronounced sigmoidal shape of their strain hardening response.

The strength of the steel/zirconia-interface is of great importance for the global mechanical behavior of the composite material. Adding small fractions of Ti is one opportunity for the initiation of reliably bonded $\mathrm{ZrO}_{2}$ particles within the steel matrix. The particle size distribution of the initial solid powder mixtures demanded a large number of organic agents to allow adequate paste processing [24, 34]. Nevertheless, the debinding settings provide samples with carbon contents of $(0.05 \pm 0.01) \%$ and which corresponded to the concentration of the as-delivered steel powder (cf. Table 5.2). Hence, the formation of carbides during high-temperature processing was

(a)

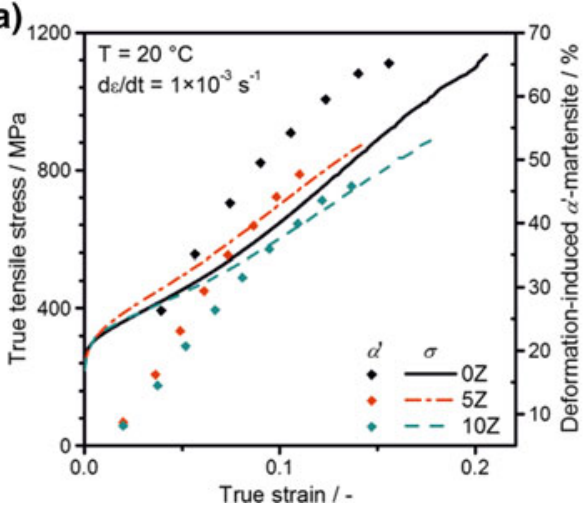

(b)

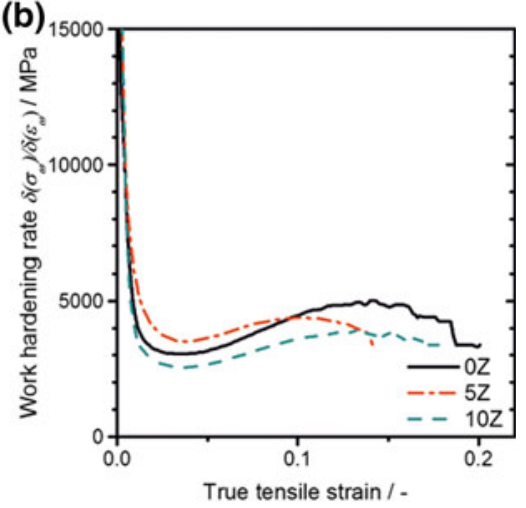

Fig. 5.9 Tensile properties of the TRIP steel and the composite variants showing the strengthening and embrittling effect of certain ceramic fractions: a flow stress curves, $\mathbf{b}$ work hardening rates [31] 
unlikely to occur. The sintered specimens appeared with a glossy metallic surface indicating the absence of considerable metal oxidation during thermal processing. Shrinkage, bulk density and porosity of all material variants considered in the frame of interface modification experiments are summarized in Table 5.6. Only small differences between the pure steel and MMC material can be recognized. The shrinkage of specimens with additions of titanium is lower than in recipes $0 \mathrm{Z} / 10 \mathrm{Z}$ but rises as a function of the Ti fraction. The calculated porosities declined from 10.7 to $4.6 \%$ by rising the titanium fraction from 1 to 3 vol\% [27].

Figure 5.10 shows representative flow curves of the quasistatic compressive loading tests at room temperature. The presence of $10 \mathrm{vol} \%$ magnesia partially stabilized zirconia particles lead to a significant increase of the compressive stress level in a wide range of deformation. At $0.2 \%$ plastic strain the pure TRIP steel specimens show an engineering stress of $206 \pm 8 \mathrm{MPa}$ and a sigmoidal stress-strain curve on further deformation that could be related to the martensitic phase transformation. In comparison, the $10 \mathrm{Z}$ composite material is characterized by a similar behavior with higher yield strength of $249 \pm 4 \mathrm{MPa}$ and advanced mechanical response at moderate strain (up to $100 \mathrm{MPa}$ higher stress level than $0 \mathrm{Z}$ ). However, the strengthening effect of material $10 \mathrm{Z}$ was exhausted when exceeding $\varepsilon_{\text {true }}=0.5$ and the stress level of the composite material dropped below the specimens without any ceramic additions (0Z). The essential material characteristics of $0 \mathrm{Z}$ and $10 \mathrm{Z}$ specimens were similar to

Table 5.6 Properties of the as-fired specimens [27]

\begin{tabular}{l|l|l|l|l|l}
\hline Recipe & SS & $10 \mathrm{Z}$ & $10 \mathrm{Z}-1 \mathrm{~T}$ & $10 \mathrm{Z}-2 \mathrm{~T}$ & $10 \mathrm{Z}-3 \mathrm{~T}$ \\
\hline Shrinkage $(\%)$ & $11.2 \pm 0.5$ & $11.4 \pm 0.2$ & $10.3 \pm 0.3$ & $10.6 \pm 0.3$ & $10.8 \pm 0.4$ \\
\hline Bulk density $\left(\mathrm{g} / \mathrm{cm}^{3}\right)$ & $7.01 \pm 0.02$ & $6.79 \pm 0.03$ & $6.77 \pm 0.04$ & $7.06 \pm 0.04$ & $7.16 \pm 0.01$ \\
\hline
\end{tabular}

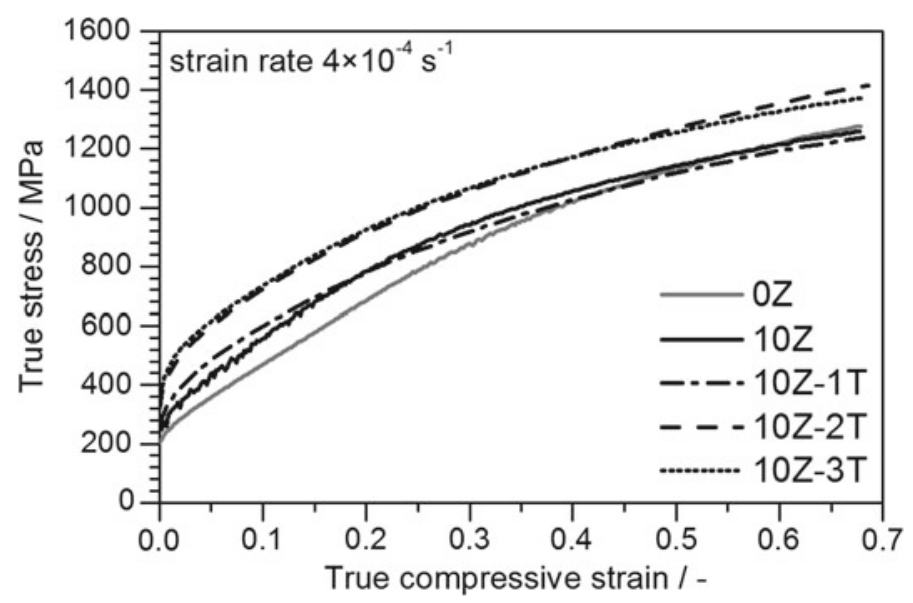

Fig. 5.10 Compression stress versus strain of the steel and the composite variants illustrating the effect of titanium [27] 
composite materials reported by Martin et al. [28]. The higher level of mechanical response could be assumed to origin from less than $2 \%$ porosity as the samples were prepared by spark plasma sintering. The influence of titanium on the mechanical properties differs in a wide range. In general the presence of Ti results in an increase of the yield strength: $260 \pm 21 \mathrm{MPa}(1 \mathrm{vol} \% \mathrm{Ti}), 327 \pm 3 \mathrm{MPa}(2 \mathrm{vol} \% \mathrm{Ti})$ and $345 \pm 4 \mathrm{MPa}$ (3 vol\% Ti). Specimens with $1 \%$ Ti exhibited higher true stresses in a certain range of strain in comparison to pure TRIP steel specimens and 10Z composite material. However, the points of intersection can be observed at a true strain of approx. 0.2 and 0.4 , respectively. The mechanical properties of composite materials with 2 and 3 vol\% titanium are almost equal.

\subsubsection{Effect of Zirconia and Aluminium Titanate on the Mechanical Properties of Composite Materials}

As already mentioned, the conventional pressureless sintering process facilitates chemical reactions, segregations, and the formation of $\delta$-ferrite in the unreinforced TRIP steel specimens and in the composite variants during firing [35] (Table 5.7). Thus, the ferromagnetic volume fraction in the as-fired state strongly depends on the material's composition and particularly on the presence of primary aluminium titanate in the material variants. The highly dense metal matrix exhibited several pores and precipitations that were characterized by high concentrations of $\mathrm{Mn}, \mathrm{Mg}$, and $\mathrm{Si}$ as measured by EDS. It was assumed that these precipitations originated from the refractory material used in the gas atomization process. In general, the steel grains exhibited segregations at grain boundaries with enhanced concentrations of $\mathrm{Cr}$ and lower concentrations of $\mathrm{Ni}$, forming $\delta$-ferrite. The pronounced transformation of the highly metastable steel from austenite to martensite on the specimens' surfaces is a result of mechanical polishing. The ferromagnetic phases $\delta$-ferrite and $\alpha^{\prime}$-martensite were confirmed by magnetic balance measurements. The presence of carbides was negligible. The characteristic microstructure of composite specimens with zirconia is shown in Fig. 5.11. The ceramic particles are randomly dispersed and widely embedded in the surrounding steel matrix. Delamination and broken-out particles indicate the loose bonding at the metal/ceramic and ceramic/ceramic interfaces. This is most likely a consequence of the firing temperature of the composite material, which was considerably below the normal sintering temperature of such zirconia ceramics $\left(>1600^{\circ} \mathrm{C}\right)$.

Table 5.7 Physical characteristics of the material variants

\begin{tabular}{l|l|l|l|l|l}
\hline Recipe & $0 Z$ & $5 Z$ & $10 Z$ & 5 AT & 10AT \\
\hline Shrinkage $(\%)$ & $15.9 \pm 0.1$ & $16.4 \pm 0.1$ & $15.9 \pm 0.1$ & $15.2 \pm 0.2$ & $12.5 \pm 0.1$ \\
\hline Bulk density $\left(\mathrm{g} / \mathrm{cm}^{3}\right)$ & $0.1 \pm 0.1$ & $0.1 \pm 0.0$ & $0.4 \pm 0.3$ & $0.4 \pm 0.4$ & $14.1 \pm 0.7$ \\
\hline Porosity $(\%)$ & $7.54 \pm 0.05$ & $7.34 \pm 0.04$ & $7.25 \pm 0.05$ & $7.26 \pm 0.05$ & $6.39 \pm 0.12$ \\
\hline
\end{tabular}



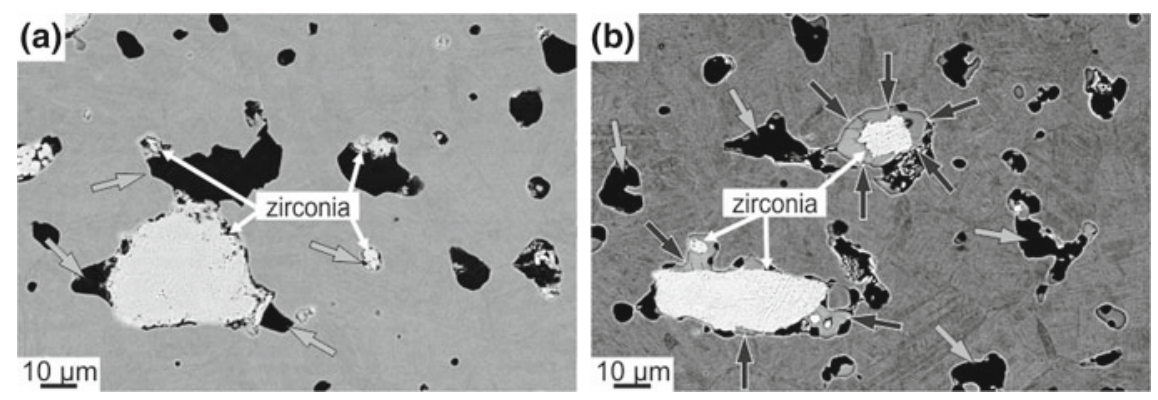

Fig. 5.11 Microstructure of MMC specimens with combinations of zirconia and aluminium titanate in their as-fired state showing the particular inclusion of zirconia particles by aluminium titanate/spinel (light grey arrows) and a solid solution of $\mathrm{Zr}-\mathrm{Ti}-\mathrm{O}$ also containing $\mathrm{Mn}$ (dark grey arrows): a 2.5ZAT, b 5ZAT [36]

The in situ tests revealed the kinetics of strain-induced $\alpha^{\prime}$-martensite during deformation. The S100 specimens exhibited the highest overall percentage of straininduced $\alpha^{\prime}$-martensite at rupture (see Fig. 5.12). The lower formation of straininduced $\alpha^{\prime}$-martensite in the composite variants 5Z/2.5ZAT was in accordance with the less pronounced sigmoidal shape of their strain hardening response. The reduction of the austenite stabilizing alloying element Mn was caused by its evaporation, diffusion and the formation of phases containing $\mathrm{Mn}$ at the metal/ceramic interfaces like $(\mathrm{Mg}, \mathrm{Mn}) \mathrm{Si}_{2} \mathrm{O}_{4}$ and/or $(\mathrm{Mn}, \mathrm{Mg})(\mathrm{Al}, \mathrm{Ti}, \mathrm{Cr})_{2} \mathrm{O}_{4}$, and led to a distinct shift of the initial metallic phase composition. This mechanism is more pronounced in MMCs

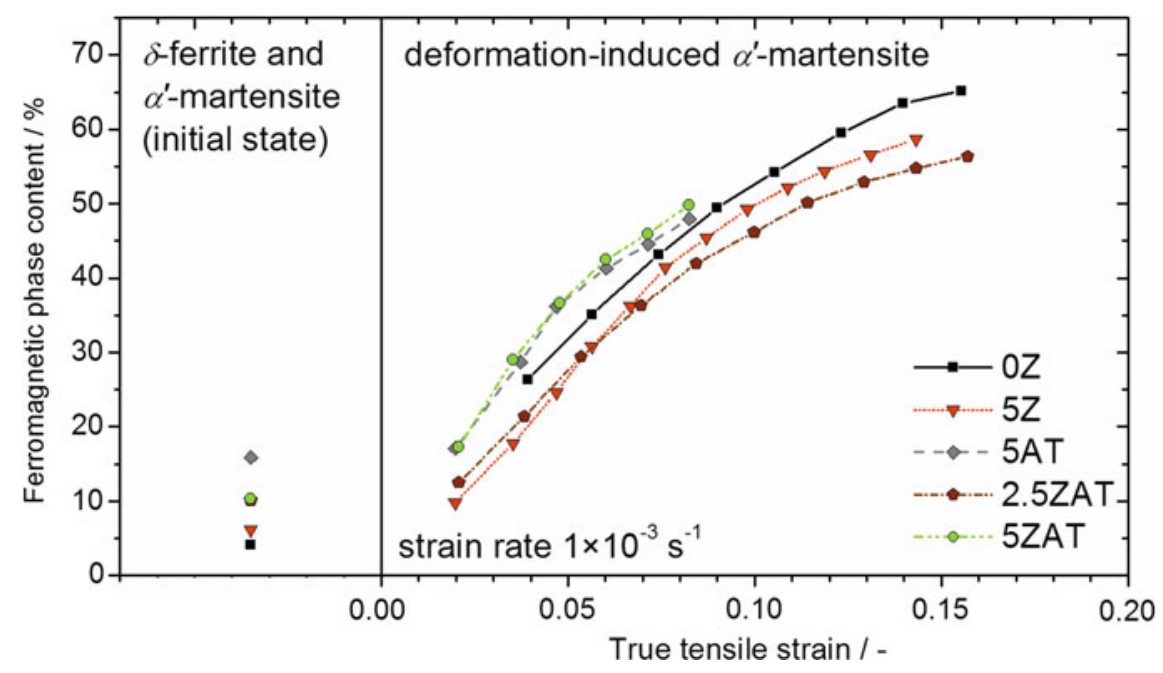

Fig. 5.12 Evolution of the ferromagnetic phase fraction under tensile deformation at room temperature, normalized by the metal fraction in the material [36] 
with aluminium titanate as compared with steel/zirconia mixtures. Hence, the composites of types 5AT and 5ZAT reveal a higher $\alpha^{\prime}$-martensite content and formation rate at the beginning of plastic deformation. Then, the constrained matrix of the work hardened austenitic/martensitic steel suffers from the lack of strain relaxation, which promotes crack initiation and propagation [36].

The microstructure of the specimens after tensile deformation tests was analyzed in order to explain the mechanical behavior as well as the characteristic failure mode of the material and is shown in Fig. 5.13. The small strengthening effect of zirconia in the MMCs is a result of the loose embedding of the Mg-PSZ particles, of the irregular formation of silicates as an intermediate layer between steel/zirconia and zirconia/zirconia particles and of the lack of pronounced metastable $\mathrm{ZrO}_{2}$ phase regions. The zirconia agglomerates are broadly crushed and fissured after tensile deformation; considerable delamination occurred at the steel/ceramic interface, which indicates loose interface boundaries [37,38]. Thus, sufficient load transfer from the steel matrix can be assumed. Still, the sintering temperature of the composite material was well below the regular sintering temperature of Mg-PSZ, thus the clustered particles are expected to fail at lower stresses as compared with the commercially available bulk material. Since the majority of the zirconia particles exhibited the non-transformable monoclinic crystal structure already after sintering, the probability of the desirable tetragonal to monoclinic phase transformation is low. However, a large amount of voids in the ceramic sections, caused by broken-out particles, hampered a detailed and representative phase analysis of the material.

It is obvious that the zirconia particles with a silicate intermediate layer and these silicate structures remained reliably bonded in the matrix material, whereas a large amount of zirconia particles was broken out after specimen preparation. The tensile deformed microstructure of MMCs with $5 \mathrm{vol} \%$ initial aluminium titanate powder is characterized by the spinel particles that maintained their pronounced interface bonding to the steel matrix despite the extended multiple-crack formation in the interior of the ceramic particles. In contrast, debonding was the dominant damage initiation mechanism in previous TRIP steel/Mg-PSZ composites [11, 38, 39]. The intact particle/matrix interfaces indicate a higher shear strength at the interface than
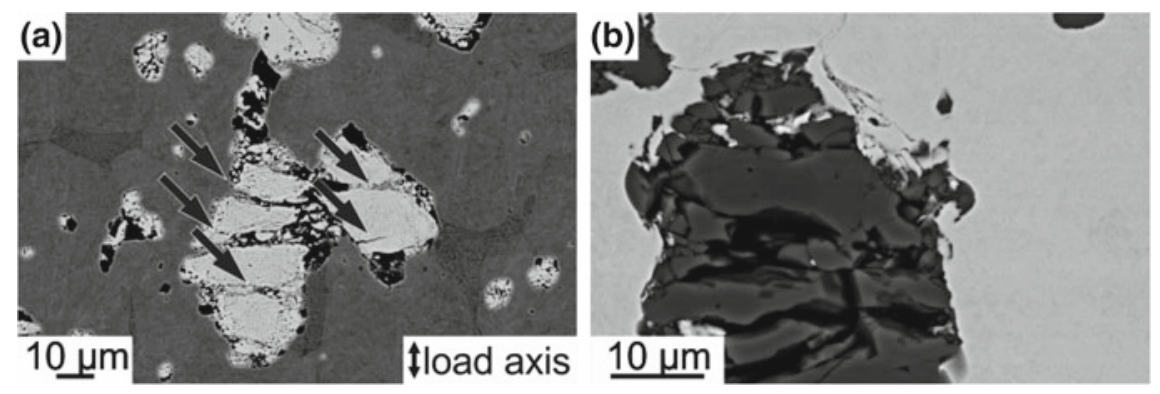

Fig. 5.13 SEM image of the composite materials at fracture strain showing broadly crushed ceramic particles and isolated cracks in the surrounding steel matrix: a 5Z, b 5AT [36] 
the particle fracture strength which is a further indication for the improved interfacerelated performance of the $\mathrm{MMCs}$ with initial $\mathrm{Al}_{2} \mathrm{TiO}_{5}$ [37, 40]. Still, some of the small-grained spinel particles were nearly intact and exhibited neither cracking nor debonding. Although these composites underwent internal damage by crack initiation and the ceramic particles show no phase transformation or decomposition as compared with composite materials comprising metastable zirconia particles [3, 28], the addition of aluminium titanate results in a higher strain-induced $\alpha^{\prime}$-martensite formation and these MMCs sustain a higher stress level than the pure matrix material. The microstructure of the composite materials with concurrent additions of Mg-PSZ and aluminium titanate largely complied with the observations on $5 \mathrm{Z}$ and 5AT and the specific features for each type of ceramic particles. Here, the zirconia particles were subject to intense cracking but less to debonding due to the formation of the Ti-enriched spinel interlayer between the $\mathrm{ZrO}_{2}$ particles and the steel matrix. The mutual interference of the zirconia particles and the initial aluminium titanate particles was apparently more pronounced in the MMCs with the higher ceramic volume fraction due to the coincidental distribution of these particles within the steel matrix [36].

The stress-strain curves of the TRIP steel alloy and the MMCs determined under compressive and tensile loading at a quasistatic strain rate of $0.001 \mathrm{~s}^{-1}$ at ambient temperature are displayed in Figs. 5.14 and 5.15. The stress level of the TRIP-matrix composites under compressive loading is significantly higher than the pure steel material considering a certain range of plastic deformation. As a consequence of damage initiation and propagation, the compression stress of material 10AT firstly dropped at approximately $11 \%$ engineering strain below the values measured for the pure steel specimen. Finally, catastrophic failure with sample fragmentation was induced achieving $45 \%$ strain. The strengthening effect of 5 vol\% Mg-PSZ was
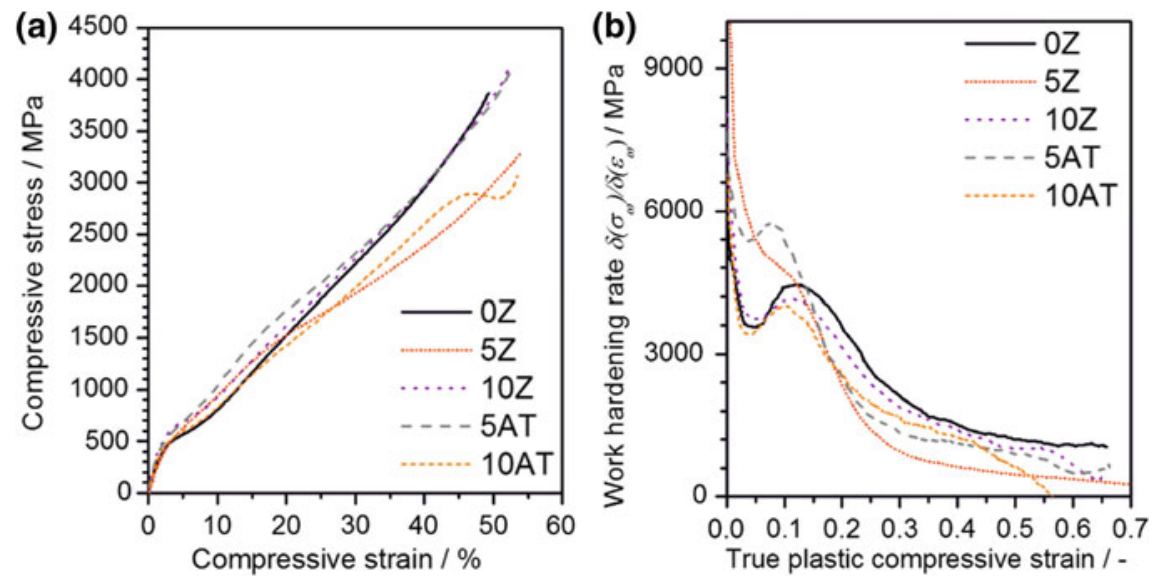

Fig. 5.14 Mechanical behavior of the specimens tested under quasistatic compression: a engineering stress-strain curves and $\mathbf{b}$ work hardening rates versus plastic compressive strain [35] 

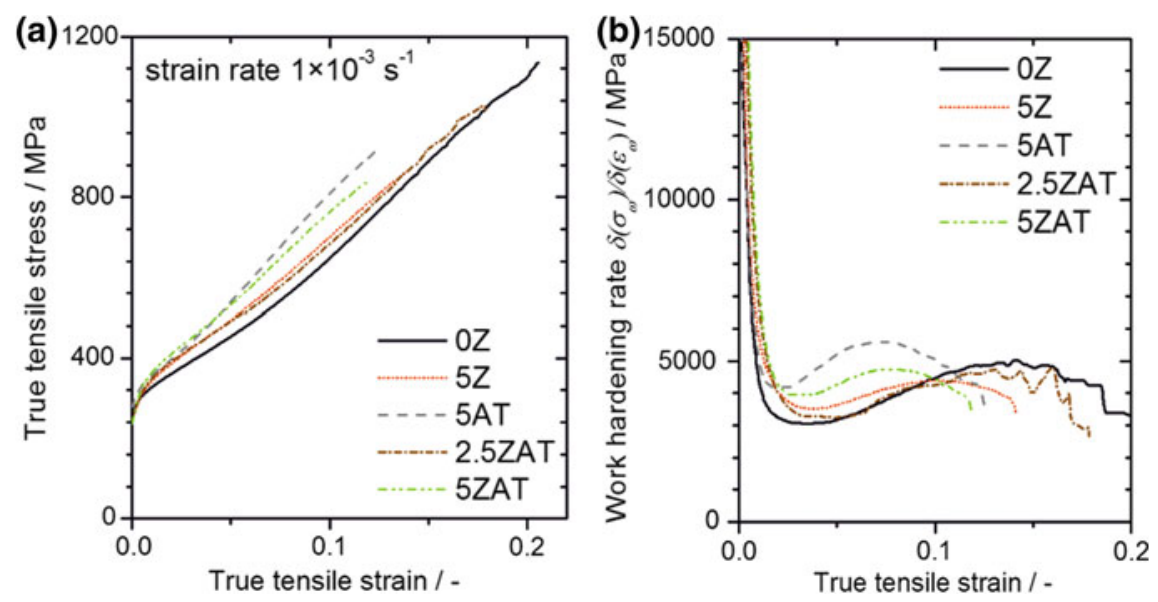

Fig. 5.15 Tensile deformation behavior of the material variants showing the strengthening and strain-depressing effect of certain ceramic fractions: a flow stress curves, $\mathbf{b}$ work hardening rates [36]

Table 5.8 Properties of the fired base materials without joining [30]

\begin{tabular}{l|l|l|l}
\hline & $0 Z$ & $5 Z$ & $10 Z$ \\
\hline Shrinkage (\%) & $16.0 \pm 0.2$ & $16.5 \pm 0.1$ & $15.9 \pm 0.2$ \\
\hline Total porosity (\%) & $4.1 \pm 1.4$ & $4.4 \pm 0.6$ & $4.5 \pm 0.5$ \\
\hline $\begin{array}{l}\text { Bulk density } \\
\left(\mathrm{g} / \mathrm{cm}^{3}\right)\end{array}$ & $7.46 \pm 0.11$ & $7.34 \pm 0.04$ & $7.24 \pm 0.04$ \\
\hline
\end{tabular}

exhausted when exceeding $18 \%$ compressive strain. However, the strain range with enhanced compressive stress compared with the pure TRIP steel was extended for the MMCs comprising $5 \mathrm{vol} \% \mathrm{Al}_{2} \mathrm{TiO}_{5}$ and $10 \mathrm{vol} \% \mathrm{Mg}$-PSZ up to approximately $45 \%$ deformation. All composite materials exhibited higher yield strengths than the variant without any ceramic additions. The work hardening rates also illustrate the strengthening effect of the ceramic particles in a certain range of strain followed by a decreasing work hardening rate on further deformation [35].

\subsubsection{Joining of Zirconia Reinforced MMCs}

The base materials for joining experiments show similar macrostructure and microstructure as compared with the standard bulk materials previously reported. The determination of the physical characteristics (shrinkage, porosity and density) of the fired specimens revealed similar properties among all base materials (see Table 5.8) regardless the ratio of zirconia particles dispersed within the steel matrix. The residual porosity of approximately $4-5 \%$ is caused by the particle size of the 


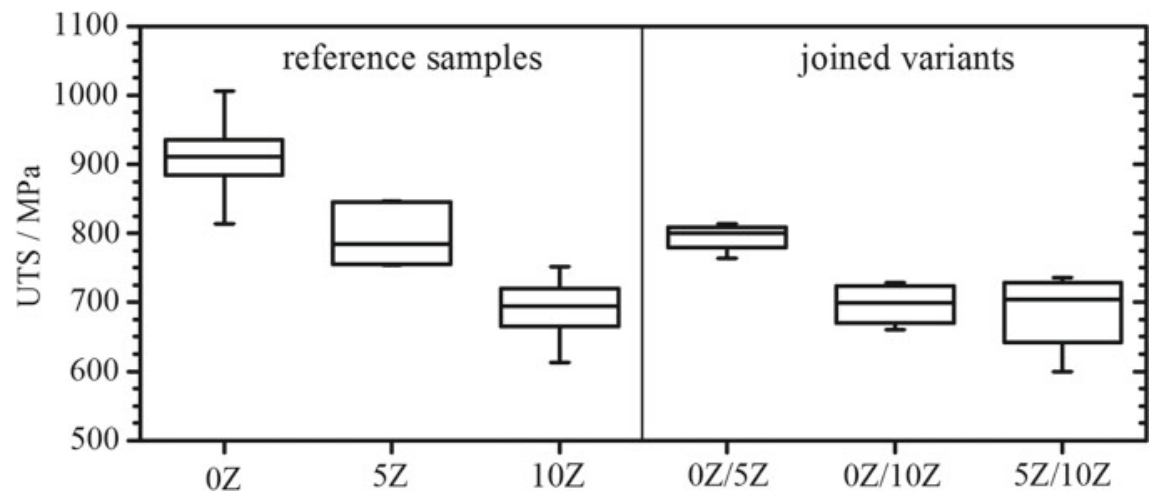

Fig. 5.16 Ultimate tensile strength of the materials tested under a quasistatic tensile loading at a rate of $0.001 \mathrm{~s}^{-1}$ at room temperature, featuring the minima, maxima and the $25 \%-, 50 \%$, , and $75 \%$-percentiles [22]

raw materials, the presence of the binder system during extrusion, and the applied pressureless sintering. The fired specimens appeared with a glossy metallic surface indicating the absence of considerable metal oxidation during thermal processing.

The results of tensile tests are given in Fig. 5.16. As expected, the composite materials had a lower ultimate tensile strength (UTS) and fracture strain as compared with the pure steel specimens. The decline of UTS by increasing the zirconia volume fraction results from the partial replacement of the ductile matrix material by brittle ceramic particles and which facilitates crack initiation and propagation.

Since the surface preparation is of major interest in joining processes, the sample preparation and material derived variations have to be taken into consideration. Nevertheless all surfaces to be joined appeared smooth with some transverse stress marks from the rotating grinding wheel indicating the definitive inclusion of the steel particles in the binder matrix in their dry green state. Break-off of particles and spalling on the edges of the samples was not observed. The addition of 5 or $10 \mathrm{vol} \%$ Mg-PSZ did not significantly affect the properties of the surface to be joined, since the ceramic particles were well dispersed and reliably fixed in the composite variants with their metal/binder matrix. The average roughness value $\mathrm{R}_{\mathrm{a}}$ of the machined joining surface of the material variants $(21.7 \mu \mathrm{m}-0 \mathrm{Z} ; 20.2 \mu \mathrm{m}-5 \mathrm{Z} ; 18.1 \mu \mathrm{m}-$ 10Z) marginally deviates among all materials tested and, thus, a preparation-driven impact on the material characteristics is not to be expected $[22,30]$.

The location of the joints could easily be assigned in the as-fired state due to some leaked paste from the joining process. The microstructure of the material combinations $0 Z / 10 Z$ and $5 Z / 10 Z$ is shown in Fig. 5.17. The base materials show a homogeneous microstructure with some pores and inclusions (all), and a good dispersion of the ceramic particles at a certain degree of agglomeration (5Z and 10Z). The smaller sized zirconia particles tended to form coarse-grained agglomerates in the interstices of the steel particles during manufacturing, which is more pronounced in the specimen with 10 vol\% zirconia. 

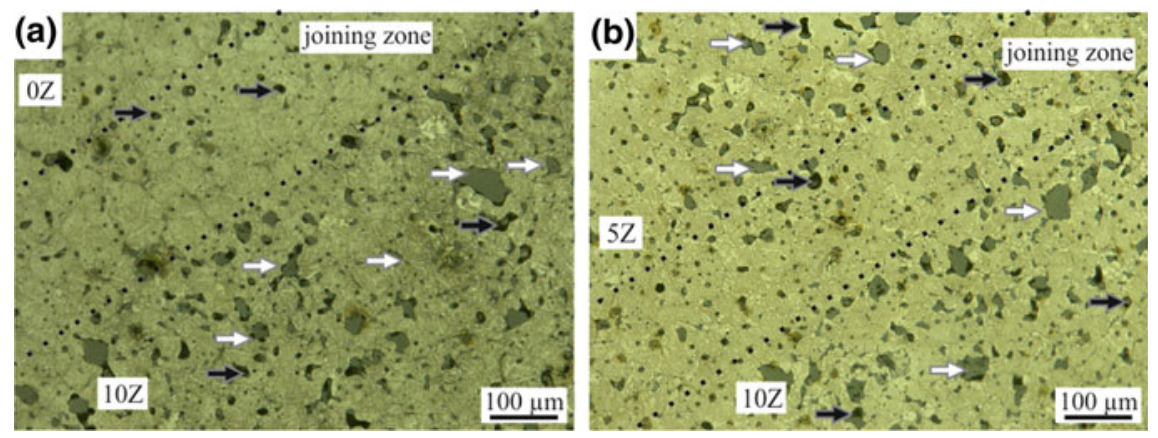

Fig. 5.17 Micrograph of sinter-joint variants: a 0Z/10Z, b 5Z/10Z; black arrows: pores and nonmetallic inclusions, white arrows: zirconia particles [22]

The formation of distinctive sections, e.g. heat-affected zone and welding seam as known from fusion welding, was neither detected by light optical microscopy nor scanning electron microscopy in the present sinter-joint samples. The joining interface is characterized by a smooth transitional area at a thickness of roughly $100-400 \mu \mathrm{m}$. The measurement of the width is only feasible in the material combination $5 Z / 10 Z$ due to an enlarged zirconia-free intersection between the base materials (see Fig. 5.17b). Contaminations and nonmetallic inclusion are present in all material variants since the pressureless sintering promotes the formation of silicates and spinels at the steel/zirconia interface and even in the pure steel material $[3,41]$. Firing the pure joining paste under equivalent thermal conditions results in the formation of a microstructure (e.g. grain size, porosity, and precipitations) similar to the fired $0 \mathrm{Z}$ base material [22].

The micro hardness profiles of the joint variants transverse to the joining zone were examined. The microstructure and the elemental distribution of the material combination $0 \mathrm{Z} / 10 \mathrm{Z}$ is shown in Fig. 5.18. Both components (0Z and $10 \mathrm{Z})$ are characterized by a similar microstructure with randomly dispersed pores and nonmetallic inclusions. The location of the joining zone could clearly be allocated by taking the presence of the zirconia particles and the concentration of Fe and $\mathrm{Zr}$ (using EDS) into consideration. The presence and concentration of $\mathrm{Si}$ is not a function of the zirconia volume fraction, since $\mathrm{Si}$ was incorporated as a contamination of the initial steel as well as of the zirconia powder (cf. Tables 5.2 and 5.3). The investigation of samples with material combinations $0 Z / 5 Z$ and $5 Z / 10 Z$ revealed similar results, however the smaller the difference in zirconia volume fractions between both joining partners, the more difficult was the localization and identification of the joining zone [22].

All joined material combinations failed at lower UTS and strain than the stronger component. The failure of all sinter-joint material combinations was initiated within the base material containing the higher volume fraction of Mg-PSZ particles. As pressureless sintering of the powder metallurgical processed composites involves thermal treatment for several hours at high temperature interactions between all components affect the microstructure and the material properties. Both the alloying elements of 

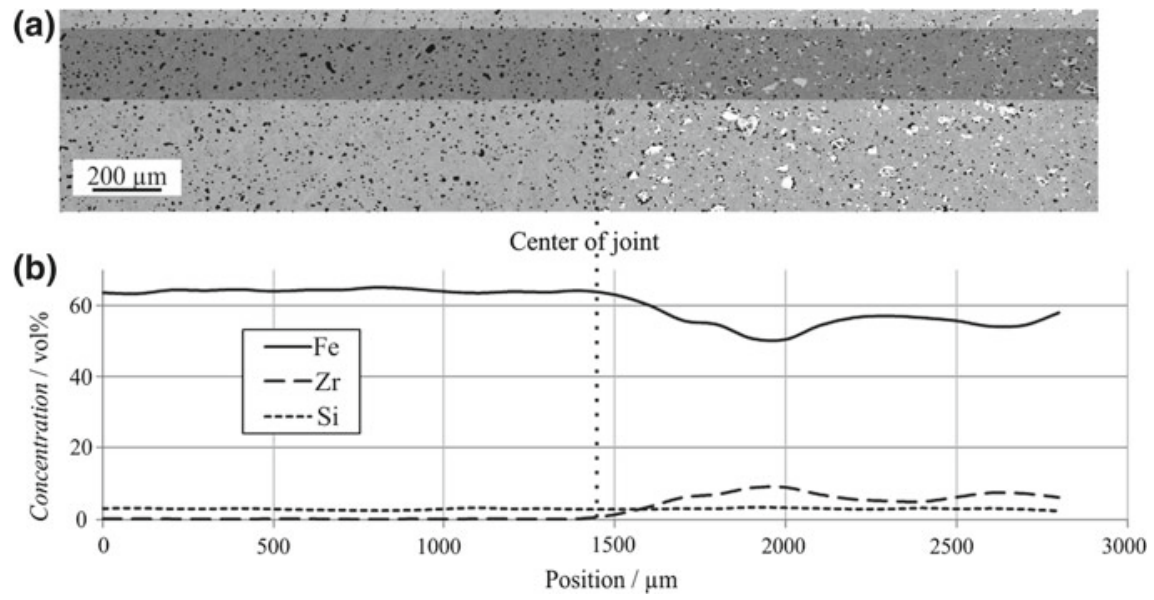

Fig. 5.18 Microstructure of combination 0Z/10Z after firing: a SEM image: dark grey: steel, light grey: zirconia; black: pores and nonmetallic inclusions, $\mathbf{b}$ transversal EDS line scan of the joint section showing the concentrations of $\mathrm{Fe}, \mathrm{Zr}$, and $\mathrm{Si}$ including the highlighted area (measuring field size $200 \mu \mathrm{m} \times 200 \mu \mathrm{m}$, step size $100 \mu \mathrm{m})$ [22]
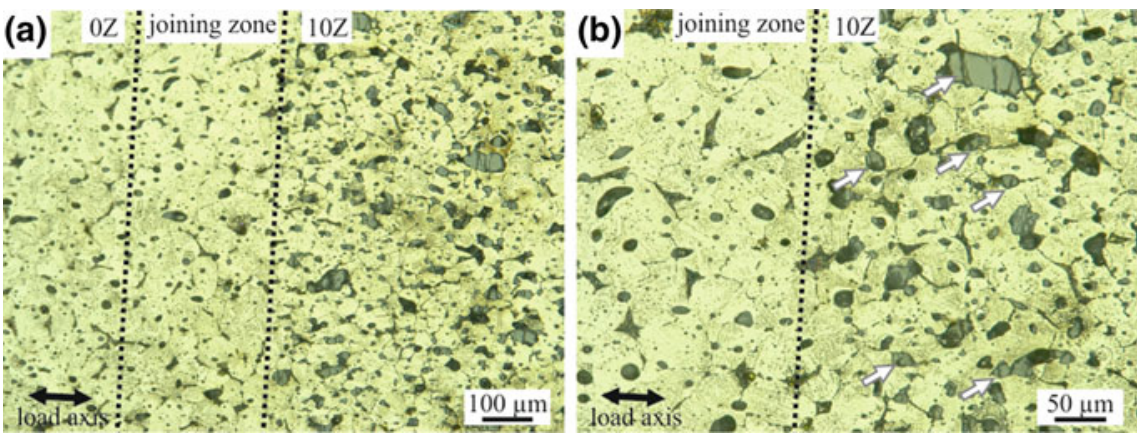

Fig. 5.19 Micrograph of the material combination 0Z/10Z after $20 \%$ tensile deformation showing particle fracture in large zirconia particles (indicated by white arrows), rare debonding at the metal/ceramic interface, and the well-preserved joining zone [22]

TRIP steel and the stabilizing agent of the zirconia reinforcing particles $(\mathrm{Mg})$ are prone to diffusional interchange [21]. However, the composite material suffers from poor interfacial bonding, which is apparently more pronounced under tensile than under compressive loading. Thus, the reinforcing particles or agglomerates debond in an early state of deformation and micro crack formation initiates MMC's failure at lower strain than the pure steel material. Also the pronounced multiple crack formation within the coarse zirconia agglomerates could be observed as shown in Fig. 5.19 [35]. In contrast, the sinter-joint appeared almost intact and the boundary surface between the joining zone and the base materials indicated no detachment [22]. 


\subsection{Conclusions}

The ceramics-derived extrusion technology has been successfully applied on the manufacturing of metallic matrix composites. The combination of austenitic stainless TRIP/TWIP steel matrix variants with certain ceramic additions at metal volume fractions $\geq 90 \%$ is feasible. Mixing solid powders with an aqueous organic binder system enables the shaping of bulk and cellular lightweight structures at room temperature. The particle size and shape of the starting powders, the metal/ceramic-ratio, and the binder system crucially affect the shaping process and the microstructure of the shaped specimens. Generally, the ceramic particles were homogeneously dispersed within the metal matrix with a certain degree of agglomeration. To improve the particle dispersion, the size distribution of the metal and the ceramic component should be narrow and compliant to avoid clustering of fine reinforcing particles in the interstices of the metal matrix. Set proper drying parameters (temperature, heating rate) prevents the material from detrimental crack formation and damage of the materials. The subsequent thermal processing comprising the binder removal (debindering) and the consolidation (sintering) transfers the material into its final state. Pressureless sintering of the powder metallurgically processed materials requires temperatures slightly below the metal melting temperature with maximum temperatures of $1300-1400{ }^{\circ} \mathrm{C}$ and distinct dwell time of 1-2 h. The thermally induced diffusional interchange of the alloying elements of the steel and the ceramic fractions led to mutual alterations of the components. The crystal structure of zirconia in the MMCs was predominantly monoclinic due to diffusion of $\mathrm{Mg}$ out of the particles and the formation of spinel and/or silicate precipitations at the steel/zirconia interface during firing. Thus, the desired tetragonal to monoclinic transformation of the zirconia particles during mechanical testing is hampered.

The reinforcing mechanism of ceramic particles dispersed in TRIP/TWIP steel matrices enables composite materials with superior mechanical properties in a certain range of deformation. The stress-strain and deformation behavior of the materials were mainly controlled by dislocation hardening and $\alpha^{\prime}$-martensite phase formation in the steel matrix further affected by the reinforcing mechanisms of the ceramic particles. Finally, all composite materials failed at a lower strain than the unreinforced matrix material by internal damage after cracks have initiated in the steel matrix surrounding the ceramic particles and which is more pronounced under compressive deformation than under tensile loading. Advanced properties of the composite variants have been observed in terms of higher compressive stresses as well as an improved energy absorption capability. The desired martensitic phase transformation was proven in both, the matrix material and the zirconia particles with pronounced phase evolution in an early stage of deformation. Upon exceeding a critical strain the materials without ceramic additions benefit from the lack of non-plastic particles leading to higher strength at equivalent deformation. The addition of 1-2 vol\% titanium improves the densification of the matrix material and the firm incorporation of zirconia particles into steel matrix. The formation of a $\mathrm{Ti}-\mathrm{Zr}-\mathrm{O}$ solid solution was observed at the metal/ceramic interface that promotes reliable interface boundary. 
Aluminium titanate was identified as a proper reinforcing material for TRIP/TWIP composite materials in the frame of the present study. The diffusional interchange of the alloying elements of the steel and the aluminium titanate particles led to the decomposition of the aluminium titanate and the formation of a dense $(\mathrm{Mn}, \mathrm{Mg})(\mathrm{Al}$, $\mathrm{Ti}, \mathrm{Cr})_{2} \mathrm{O}_{4}$ spinel structure during firing. The intergranular bonding strength and the toughness of the metal/ceramic interfaces seem to be higher than in composites with loosely embedded zirconia particles. The composite materials with aluminium titanate offered a significant strengthening effect and a distinctive strain hardening under quasistatic compressive and tensile loading as compared with the matrix material. The void-free interface between the steel and the spinel structures of the initial microstructure offered optimal conditions for the load transfer; the intergranular bonding strength and the toughness of the metal/ceramic interfaces are assumed to be higher than in composites with zirconia particles. The combination of Mg-PSZ and $\mathrm{Al}_{2} \mathrm{TiO}_{5}$ further improved the stress level of the MMCs during deformation.

An innovative technique for joining metal-matrix composite materials with minor fractions of zirconia reinforcing particles was studied. The bulk specimens were prepared with the powder metallurgical processing route via extrusion of plastic pastes at room temperature. Various combinations of the base materials with 0,5 or $10 \mathrm{vol} \%$ zirconia were joined by applying an aqueous high-solids paste on the surfaces to be joined in their dry green state at room temperature. The preparation of the surfaces before joining comprised cutting and rotary grinding with low mechanical and thermal impact on the base materials. During consecutive thermal processing the material's consolidation and the generation of the joint took place simultaneously. Thus, the formation of a consistent metal-matrix composite material and the formation of high bonding strength were initiated. Microstructural analysis revealed a homogeneous structure without inhomogeneities within the metal matrix nor segregation of the ceramic particles. Since the sintering and joining proceeded simultaneously the formation of a heat-affected influence zone as known from metal joints prepared by brazing or welding did not occur. The hardness of the pure steel specimens, the composite materials and the joining zone was measured in terms of Vickers's indention method. Since the fired specimens showed certain porosity and precipitations, the addition of zirconia particles showed no excessive hardening in the composite materials. Also, the formation of the joining zone had a negligible effect on the micro hardness. Mechanical tests under quasistatic tension at room temperature revealed similar strength of the joint variants as compared with the base materials. Strength and plasticity decreased as soon as ceramic particles were present in the base materials. Therefore, the deformation behavior of the joint variants is closely related to the mechanical properties of the base materials. In general the failure is initiated within the joining partner with the higher zirconia volume fraction without fracture at the bonding interface. The sinter joining technology is applicable for a wide range of material combinations and geometries. Efforts to improve the mechanical properties of joint materials demand improved base materials, since the materials are prone to fail beyond the joint. 
Acknowledgements The authors gratefully acknowledge the financial support of the Deutsche Forschungsgemeinschaft (DFG, German Research Foundation) for funding the research project A5 and transfer project T1 within the frame of the Collaborative Research Center 799-TRIP-MatrixComposites - project number 54473466. Additionally, the authors thank all technical employees and students who were involved in processing, machining, and analyzing the materials.

\section{References}

1. S. Martin, S. Wolf, U. Martin, L. Krüger, Solid St. Phenom. 172-174, 172 (2011)

2. H. Biermann, J. Solarek, A. Weidner, Steel Res. Int. 83, 512 (2012)

3. C. Weigelt, C.G. Aneziris, H. Berek, D. Ehinger, U. Martin, Adv. Eng. Mater. 14, 53 (2012)

4. A. Weiß, H. Gutte, M. Radke, P.R. Scheller, Patent No. WO 002008009722A1 (24.08.2008)

5. M. Hajizamani, H. Baharvandi, Adv. Mater. Ph. Chem. 1, 5 (2011)

6. E.G. Okafor, V.S. Aigbodion, Tribol. Ind. 32, 31 (2010)

7. K. Kaur, O.P. Pandey, J. Alloys Compd. 503, 410 (2010)

8. D. Wittig, A. Glauche, C.G. Aneziris, T. Minghetti, C. Schelle, T. Graule, J. Kuebler, Mater. Sci. Eng., A 488, 6 (2008)

9. L.M. Peng, J.W. Cao, K. Noda, K.S. Han, Mater. Sci. Eng., A 374, 9 (2004)

10. Y. Guo, Y. Zhou, X. Duan, D. Li, T. Lei, J. Mat, Sci. Technol. 19, 137 (2003)

11. A. Glage, C. Weigelt, J. Räthel, H. Biermann, Int. J. Fatigue 65, 9 (2014)

12. S. Decker, L. Krüger, S. Richter, S. Martin, U. Martin, Steel Res. Int. 83, 521 (2012)

13. Y. Guo, Y. Zhou, X. Duan, D. Li, T. Lei, Ceram. Int. 30, 6 (2004)

14. S.S. Panda, A. Upadhyaya, D. Agrawal, J. Mater. Sci. 42, 966 (2007)

15. C.G. Aneziris, W. Schärfl, B. Ullrich, J. Europ. Ceram. Soc. 27, 3191 (2007)

16. K. Lemster, T. Graule, J. Kuebler, Mater. Sci. Eng., A 393, 229 (2005)

17. D. Sciti, A. Bellosi, L. Esposito, J. Europ. Ceram. Soc. 21, 8 (2001)

18. W.B. Hanson, K.I. Ironside, J.A. Fernie, Acta Mater. 48, 4 (2000)

19. C. Lin, D. Gan, P. Shen, J. Am. Cer. Soc. 71, 6 (1988)

20. R.F. Domagala, S.R. Lyon, R. Ruh, J. Am. Cer. Soc. 56, 584 (1973)

21. C. Weigelt, S. Giersberg, C. Wenzel, C.G. Aneziris, Adv. Eng. Mater. 12, 486 (2010)

22. C. Weigelt, H. Berek, C.G. Aneziris, R. Eckner, L. Krüger, Mater. Sci. Forum 825-826, 498 (2015)

23. C.G. Aneziris, W. Schärfl, H. Biermann, U. Martin, Int. J. Appl. Ceram. Technol. 6, 727 (2009)

24. C. Weigelt, C.G. Aneziris, A. Yanina, S. Guk, Steel Res. Int. 82, 1080 (2011)

25. H. Biermann, U. Martin, C.G. Aneziris, A. Kolbe, A. Müller, W. Schärfl, M. Herrmann, Adv. Eng. Mater. 11, 1000 (2009)

26. P.A. Evans, R. Stevens, J. Binner, Br. Ceram. Trans. 83, 39 (1984)

27. C. Weigelt, H. Berek, C.G. Aneziris, S. Wolf, R. Eckner, L. Krüger, Ceram. Int. 41, 2328 (2015)

28. S. Martin, S. Richter, S. Decker, U. Martin, L. Krüger, D. Rafaja, Steel Res. Int. 82, 1133 (2011)

29. M.P. Phaniraj, D.K. Kim, J.H. Shim, Y.W. Cho, Acta Mater. 57, 9 (2009)

30. C. Weigelt, E. Jahn, H. Berek, C.G. Aneziris, R. Eckner, L. Krüger, Adv. Eng. Mater. 17, 1357 (2015)

31. C. Weigelt, C.G. Aneziris, R. Eckner, L. Krüger, in Proceeding of the World PM2016 Congress and Exhibition, The European Powder Metallurgy Association, Hamburg, Germany, 9-13 Oct 2016

32. W. Zhang, J. Xie, C. Wang, Mater. Sci. Eng., A 382, 387 (2004)

33. S. Noh, A. Kimura, T.K. Kim, Fusion Eng. Des. 89, 1746 (2014)

34. Z. Chen, K. Ikeda, T. Murakami, T. Takeda, J. Am. Cer. Soc. 83, 1081 (2000)

35. C. Weigelt, C.G. Aneziris, D. Ehinger, R. Eckner, L. Krüger, C. Ullrich, D. Rafaja, J. Compos. Mater. 49, 3567 (2015) 
36. C. Weigelt, G. Schmidt, C.G. Aneziris, R. Eckner, D. Ehinger, L. Krüger, C. Ullrich, D. Rafaja, J. Alloys Compd. 695, 9 (2017)

37. N. Chawla, Y.-L. Shen, Adv. Eng. Mater. 3, 357 (2001)

38. R. Eckner, M. Krampf, C. Segel, L. Krüger, Mech. Compos. Mater. 51, 707 (2016)

39. M. Droste, H. Biermann, Mater. Sci. Forum 825-826, 176 (2015)

40. S. Prüger, L. Mehlhorn, U. Mühlich, M. Kuna, Adv. Eng. Mater. 15, 542 (2013)

41. H. Berek, A. Yanina, C. Weigelt, C.G. Aneziris, Steel Res. Int. 82, 1094 (2011)

Open Access This chapter is licensed under the terms of the Creative Commons Attribution 4.0 International License (http://creativecommons.org/licenses/by/4.0/), which permits use, sharing, adaptation, distribution and reproduction in any medium or format, as long as you give appropriate credit to the original author(s) and the source, provide a link to the Creative Commons license and indicate if changes were made.

The images or other third party material in this chapter are included in the chapter's Creative Commons license, unless indicated otherwise in a credit line to the material. If material is not included in the chapter's Creative Commons license and your intended use is not permitted by statutory regulation or exceeds the permitted use, you will need to obtain permission directly from the copyright holder. 